Portland State University

PDXScholar

1978

\title{
An investigation of arsenic(V)-catechol complexes
}

Ronald P. Haak

Portland State University

Follow this and additional works at: https://pdxscholar.library.pdx.edu/open_access_etds

Part of the Chemistry Commons

Let us know how access to this document benefits you.

\section{Recommended Citation}

Haak, Ronald P., "An investigation of arsenic(V)-catechol complexes" (1978). Dissertations and Theses. Paper 2849.

https://doi.org/10.15760/etd.2843

This Thesis is brought to you for free and open access. It has been accepted for inclusion in Dissertations and Theses by an authorized administrator of PDXScholar. Please contact us if we can make this document more accessible: pdxscholar@pdx.edu. 
AN ABSTRACT OF THE THESIS OF Ronald P. Haak for the Master of Science in Chemistry presented June 9, 1978.

Title: An Investigation of Arsenic(V) - Catechol Complexes

APPROVED BY MEMBERS OF THE THESIS COMMITTEE:

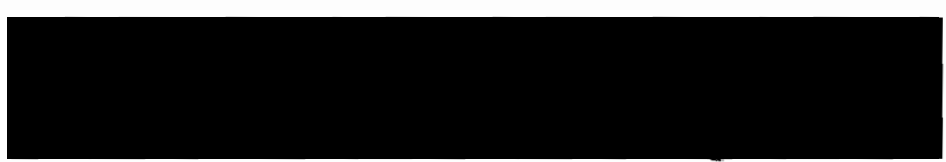

David K. Roe, Chairman
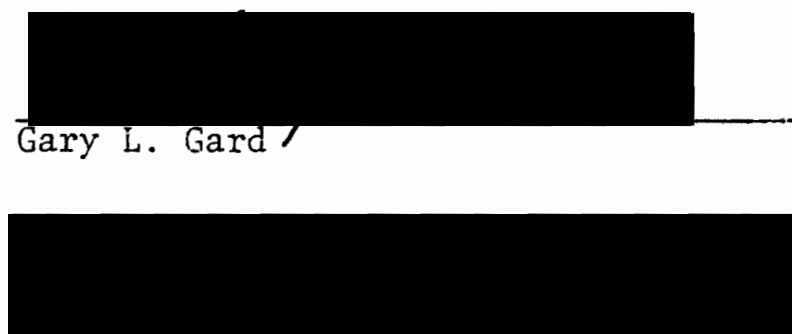

Dennis W. Barnum

There is not, at this time, a simple method for the simultaneous determination of As (III) and As (V) at trace levels. The development of such a method is needed, as the toxicities of these two species differ so greatly.

As(III) and As(V) are polarographically reducible in the presence of excess catechol, but the wave produced by $A s(V)$ is dependent on time, $\mathrm{pH}$ and catechol concentration as well as $\mathrm{As}(\mathrm{V})$ concentration. In order to understand this behavior, determination of formation constants for any complex species present were needed to identify which species is electroactive. The literature to date on the subject of As (V) - catechol compounds has shown that there is not a thorough understanding of what species are present and what their stabilities are. 
By potentiometrically measuring the amount of protons liberated in the reaction between $\mathrm{H}_{3} \mathrm{AsO}_{4}$ and catechol it was found that $\beta_{1} \simeq 0.01$ $\beta_{2} \simeq 0.02, \beta_{3}=7.5 \pm 1$. It appears that all the complexes are moderately acidic and have $\mathrm{pK}_{\mathrm{a}}<1$. While the tris complex is by far the predominant species, by comparing distribution curves of the complexes as a function of catechol concentration and the limiting current produced polarographically as a function of catechol concentration it was found that the $1: 1$ complex is the reducible species. Together with rate information about the reactions involved, the time-concentration behavior of the reduction wave was explained. 
AN INVESTIGATION OF ARSENIC(V)-CATECHOL COMPLEXES

by

RONALD P. HAAK

A thesis submitted in the partial fulfillment of the requirements for the degree of

MASTER OF SCIENCE

in

CHEMISTRY

Portland State University

1978 
TO THE OFFICE OF GRADUATE STUDIES AND RESEARCH:

The members of the Committee approve the thesis of Ronald P. Haak presented 9 June 1978.

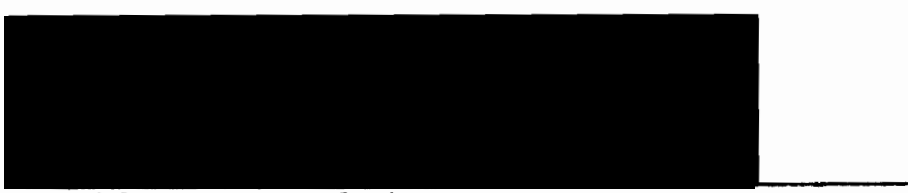

David K. Roe, Chairman
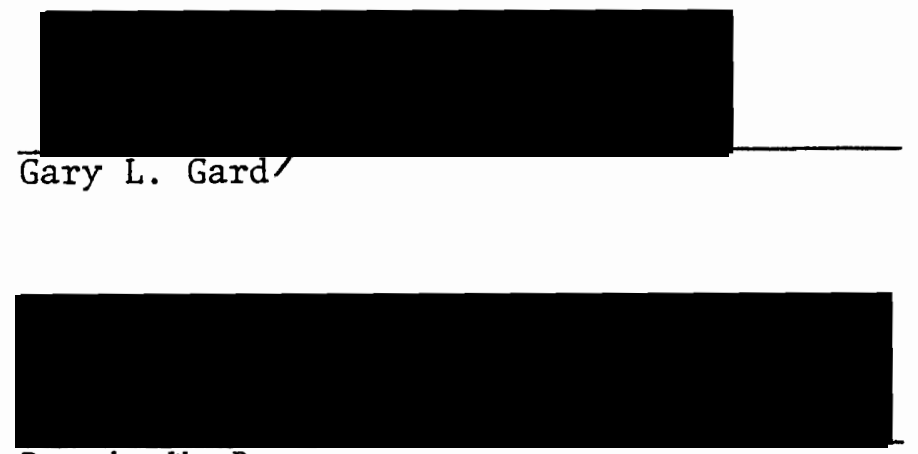

Dennis W. Barnum

APPROVED :

David W. McClure, Chairman, Department of Chemistry

Stanley E. Rauch, Dean of Graduate Studies 


\section{ACKNOWLEDGEMENTS}

I would like to thank all those who, throughout the course of this research, were willing to offer advice or supply a patient ear, particularily Dr. D. Roe. Special thanks to Dr. T. Loehr of the Oregon Graduate Center for running the Raman spectra. Finally, thanks to Kathy for helping prepare this manuscript. 
TABLE OF CONTENTS

PAGE

ACKNOWLEDGEMENTS

iii

LIST OF TABLES $\ldots \ldots \ldots \ldots \ldots \ldots \ldots \ldots \ldots \ldots \ldots \ldots \ldots \ldots \ldots$

LIST OF FIGURES $\ldots \ldots \ldots \ldots \ldots \ldots \ldots \ldots \ldots \ldots \ldots \ldots \ldots \ldots \ldots$

INTRODUCTION $\ldots \ldots \ldots \ldots \ldots \ldots \ldots \ldots \ldots \ldots \ldots \ldots \ldots \ldots \ldots \ldots \ldots \ldots \ldots$

MATERIALS AND APPARATUS $\ldots \ldots \ldots \ldots \ldots \ldots \ldots \ldots \ldots \ldots \ldots \ldots \ldots$

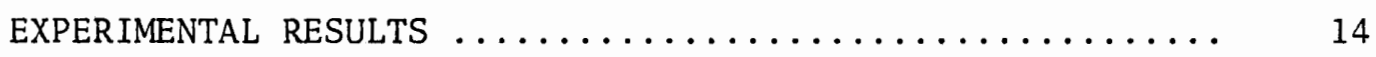

Potentiometric Titrations ................ 14

Measurements of the Liberation of Protons in the

Reaction Between $\mathrm{H}_{3} \mathrm{AsO}_{4}$ and Catechol $\ldots \ldots \ldots \ldots \ldots$

Temperature Study of the NMR Spectra of

the $1: 3$ Complex ....................... 25

Raman Spectra of As (V)-Catechol Mixtures ......... 25

Polarography of As (V) Catechol System .......... 33

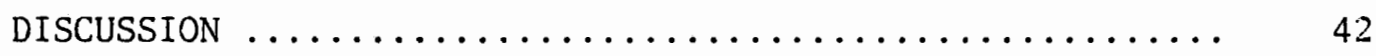

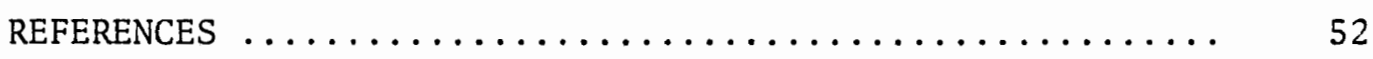

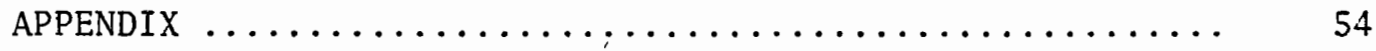




\section{LIST OF TABLES}

TABLE

PAGE

I Distribution of Species as a Function of

Catechol Concentration at $\mathrm{pH}=1 \ldots \ldots \ldots 23$

II Distribution of Species as a Function of

Catechol Concentration at $\mathrm{pH}=2 \ldots \ldots \ldots . .24$

III Summary of Raman Peaks Due to Complex

Formations or Free Catechol .......... 32

IV Summary of the Kinetic Behavior of the

Polarographic Wave Obtained From

Solutions Prepared From the 1:3

Complex ...................... 40

V Comparison of Equilibrium Constants ......... 45

VI Kinetic Current Dependence on $\mathrm{pH} \ldots \ldots \ldots \ldots . \ldots$ 


\section{LIST OF FIGURES}

FIGURE

1 Proposed Structures for the 1:3 As(V):Catechol

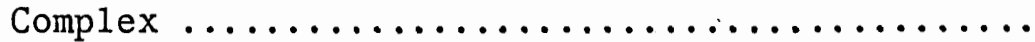

2 Titration Curves of As (V)-Catechol Mixtures ........

3 Titration Curves of Solutions Prepared From the

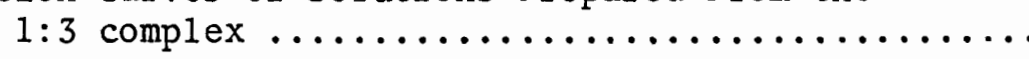

4 Evaluation of Formation Constants Assuming $\beta_{1} \ldots \ldots \ldots$

5 Evaluation of Formation Constants Assuming $\beta_{1} \ldots \ldots \ldots$

6 NMR Spectrum of Catechol in $D_{2} \mathrm{O}$ at $25^{\circ} \mathrm{C}$

Raman Spectrum of $0.5 \mathrm{M}$ Catechol

10 Raman Spectrum of 0.1:0.7M As (V):Catechol Solution ....

11 Polarogram of As (V)-Catechol Mixture $\ldots \ldots \ldots \ldots \ldots$

12 Polarogram of As $(\mathrm{V})$-Catechol Mixture $\ldots \ldots \ldots \ldots \ldots$

13 Dependence of Limiting Current on $\mathrm{pH}$ and Catechol Concentration

14 Effect of Mercury Height on Limiting Current ........

15 Polarogram of Solution Prepared From Solid 1:3

Complex

Effect of Mercury Height on Current

17 Current Dependence on Time and Catechol Concentration .

18 Dependence of Limiting Current on $\mathrm{pH} \ldots \ldots \ldots \ldots \ldots \ldots$

19 Distribution Curves for As (V)-Catechol System, $\mathrm{pH}=1 \ldots$ 


\section{INTRODUCTION}

It is well known that various oxidation states of arsenic are more toxic than others. As( $V$ ) is oniy about one-tenth as toxic as As(III) (1). Arsine gas is extremely toxic in concentrations as low as $0.3 \mathrm{mg} / \mathrm{m}^{3}$ (2). In addition to its natural occurence, arsenic (usualiy As(III)) has been used extensively as a herbicide and has therefore been found in increasing concentrations in natural water systems. It would be much more advantageous when determining the amount of arsenic present, to be able to distinguish between these oxidation states.

The methods used for arsenic analysis are quite varied. A standard method now employed utilizes a red colored complex resulting from a reaction between arsine and silver diethyldithiocarbamate. This analysis has a working range of 1-20 $\mathrm{kg}$ of arsenic (about 1ppm) (4). Atomic absorption (5) and emission spectroscopy (4) have given low detection limits but also require the generation of arsine gas and do not distinguish between the oxidation states. Isotope dilution (6) and a colorimetric method (7) can be used to determine the distribution between $A s(V)$ and As(III) but these methods tend to be slow and insensitive. A complete review of methods used for arsenic determinations has been compiled by Talmi and Feldman (8).

Historically, electrochemical tachniques have often been able to combine low limits of detection and the ability to distinguish 
between the various oxidation states of a metal. There has been an ongoing attempt since the mid $1950^{\prime} \mathrm{s}$ to develope potentiometric and voltammetric methods to be used for arsenic analysis.

Fabrication of an arsenate selective electrode has been attempted and met with limited success (9). Whereas nernstian response was found over a reasonable arsenate concentration range $\left(10^{-2}-10^{-4} \mathrm{M}\right)$, this range was too high to be applicable to trace analysis.

Ridgeway et al. $(10,11)$ have utilized differential pulse polarography to study the reduction of various alkyl and aromatic arsinic and arsonic acids. They found all the waves are irreversible, using cyclic voltammetry, but give linear response for $i_{p}$ vs. concentrations and detection limits of about 0.1-1ppm, depending upon the organic group present. They note that studies are needed to elucidate the electrode reaction mechanism. The half wave potentials were found to be $\mathrm{pH}$ dependent and they speculate that it is the protonated form of the acid that actually undergoes the initial charge transfer. They also found that the limiting current is not entirely diffusion controlled.

Anodic stripping voltammetry (ASV) has been used by Matson. et al. (12) to determine total arsenic and could conceivably be used to distinguish between $A s(V)$ and $A s(I I I)$. The procedure reported consisted of an initial reduction step of As(V) to As(III) using $1 \% \mathrm{Cu}_{2} \mathrm{Cl}_{2}$ in $37 \% \mathrm{HCl}$ solution. $\mathrm{AsCl}_{3}$ vapor was generated from this solution and was collected in deionized water, which was analyzed for arsenic by ASV. This method appears to be accurate to the nanogram level and shows excellent selectivity. It was speculated 
that by first running the analysis in the absence of $\mathrm{Cu}_{2} \mathrm{Cl}_{2}$, to allow for the detection of the As(III) alone and then reducing the As(V) to As(III) and repeating the measurement, the concentrations of both species might be measured.

Polarography has been the one method where the simultaneous determination of both $A s(V)$ and As(III) is possible. Meites (13) found that both species produced reduction waves in $12 \mathrm{M} \mathrm{HCl}$, but the wave associated with $A s(V)$ is not well defined. Bard and White (14) studied the polarographic waves resulting from the reduction of As(V) and As(III) in the presence of pyrogallol. Arsenate solutions show a three step wave corresponding to the reduction steps As(V) $\rightarrow$ As (III) $\rightarrow$ As $(0) \rightarrow$ As $(-I I I)$. From the first wave they calculated a diffusion coefficient for the As(V) -pyrogallol species of $1.7 \times 10^{-7} \mathrm{~cm} / \mathrm{s}$ which suggested a bulky, slow moving complex. Polarograms arising from the reduction of As(III) in the absence and presence of pyrogallol showed little difference, which suggested to Bard that As(III) is not complexed by pyrogallo1. Comparing $E_{\frac{1}{2}}$ values for the different steps of the $A s(V)$ and As(III) reduction waves indicated the As(V) pyrogallol complex proceeds to uncomplexed As(III).

The determination of As(III) at the parts per billion level was demonstrated by Myers and Osteryoung (15) utilizing differential pulse polarography. In a $1 \mathrm{M} \mathrm{HCl}$ electrolyte, response is linear from $0.3 \mathrm{Hg} / 1$ up to $60 \mathrm{mg} / 1$. Above $60 \mathrm{mg} / 1$, it was found, As $(0)$ is apparently adsiorbed and when the concentration is up to $600 \mathrm{mg} / 1$ the current becomes independent of As(III) concentraticn. By using methylene blue, analysis of solutions with the As(III) concentration between 60 and 
$600 \mathrm{mg} / 1$ is possible.

Roe (16) observed that $A s(V)$ in the presence of catechol as well as pyrogallol produces a reduction wave. These waves are time dependent. The current increases to a maximum and subsequently decays to a minimum. Holding the As(V) concentration and drop time constant it was found the maximum and final current and the rate of the rise and fall of the current are functions of $\mathrm{pH}$ and catechol concentration.

While it has been demonstrated by the forementioned researchers that As(III) can be determined at trace levels by voltammetric techniques there has yet to be a system where As $(V)$ can be determined at these low levels simultaneously with As(III). The arsenate-catechol system showed promise as a polargraphic technique, demonstrated by Bard and White (14), for such an analysis. In order to rationalize the data obtained thus far, a thorough understanding of the arsenate catechol system is needed. From the identification and determination of formation constants for any complexes present the species which is responsible for the reduction wave could be identified and conditions adjusted to maximize its concentration.

Weinland and Heinzler (17) first prepared an arsenate-catechol complex in 1919 by adding catechol to a boiling aqueous solution of arsenic acid. Upon standing over a period of days, colorless crystals separated out which were assigned the "structure" $\mathrm{H}_{3}\left(\mathrm{O}-\mathrm{As}-\left(\mathrm{OC}_{6} \mathrm{H}_{4} \mathrm{O}{ }_{3}\right)\right.$ $\cdot 4 \mathrm{H}_{2} \mathrm{O}$. They found in all cases the compound behaves as a monobasic acid. There then arose a controversy as to the structure of the solid salt and the complex in solution. Reihley, Sapper and Kall (19) 
studied the compound and assigned structure I in Figure 1 . They based this decision on the fact that only four molecules of water could be removed from the pentahydrate and the compound behaves as a monobasic acid. Rosenheim and Plato (18) proposed structure II, Figure 1, and were able to resolve tine anion into optically active forms, compatable with their structure. Jones and Craddock (20) commented that structure I could also be optically active if the monodentate catechol and the coordinated water molecule occupied cis positions.

Jones et al. (20-24) went on to do several studies mainly concerned with their observations that upon dissolution of the levo form of the complex ion the complex loses its optical activity in acidic solution. Using the method of Mann and Watson (25) for resolution of the anion and conversion to the barium salt, Jones et al. made a series of kinetic measurements on the hydrolysis of the complex using the loss in optical activity $(20,21)$, the resulting change in $\mathrm{pH}$ of the solution (20), and the change in conductance of the solution (22). They found that the complex is apparently stable in basic solutions (they typical1y used $10^{-2} \mathrm{M}$ solutions) but as the $\mathrm{pH}$ was lowered the rate of hydrolysis becomes measurable at about $\mathrm{pH}=3$. They found that the rate of hydrolys is is apparently first order in complex concentration and first order in hydrogen ion concentration. From titration curves obtained from the titration of solutions in which the complex acid had been dissolved they determined the $\mathrm{pK}_{\mathrm{a}}$ of the complex to be in the range of 2.75-2.2. These values bear a suspicious resemblence to $\mathrm{pk}_{1}$ for arsenic acid, which is 2.22. An important point to note here is that 

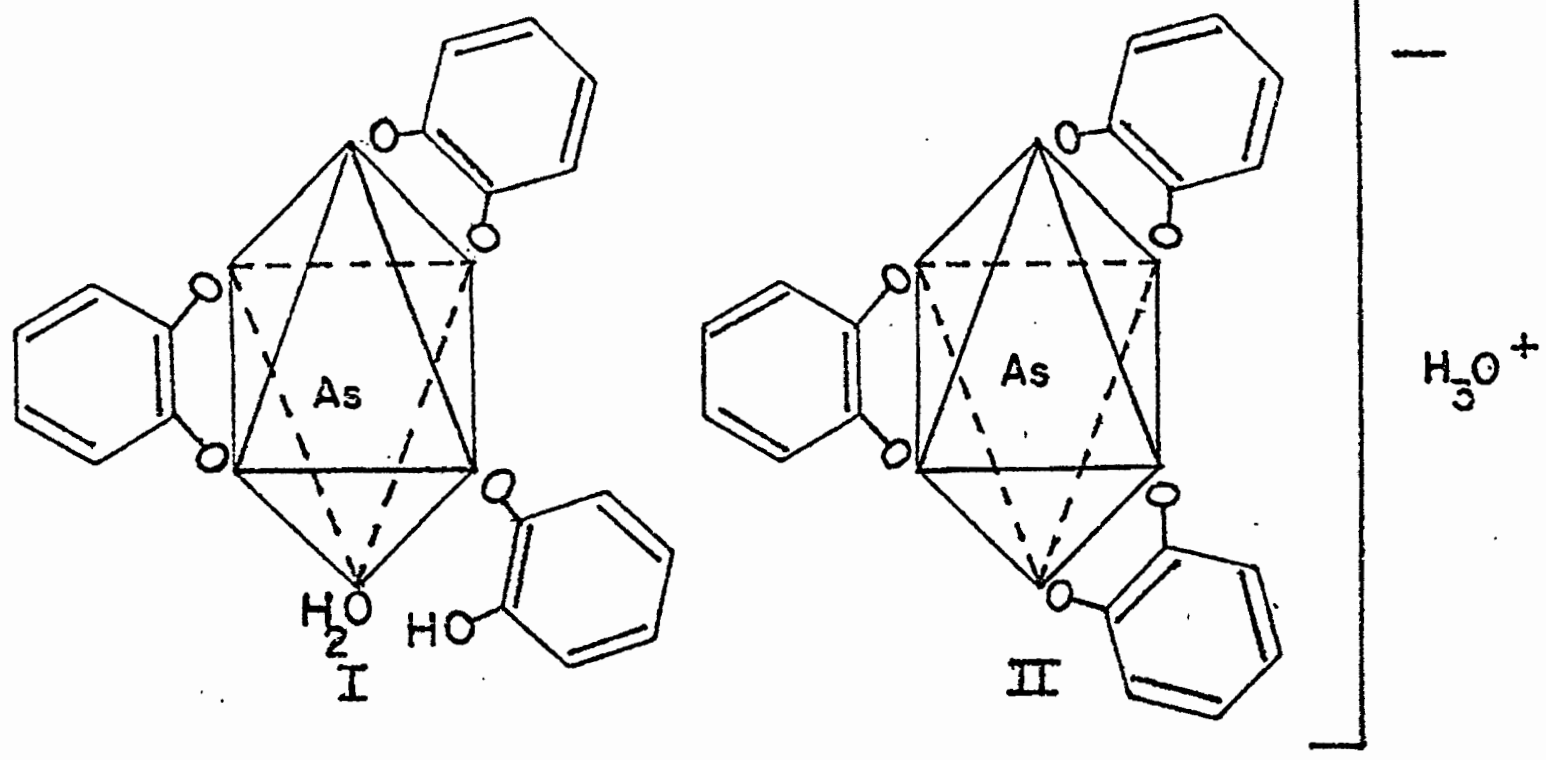

Figure 1. Proposed structure for the 1:3 As(V) catechol complex.

because of the $\mathrm{pK}_{\mathrm{a}}$ value assigned to the complex, a complete dissociation reaction is not in agreement with the experimental data. Since arsenic acid has a lower $\mathrm{pK}_{1}$ the $\mathrm{pH}$ would fall, not, rise as was observed. The equilibria: proposed by Jones et al, is:

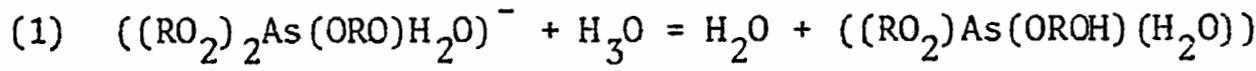

(2) $\left(\left(\mathrm{RO}_{2}\right)_{2} \mathrm{As}(\mathrm{OROH}) \mathrm{H}_{2} \mathrm{O}\right)=\left(\mathrm{RO}_{2}\right) 2^{\mathrm{AsOH}}+\mathrm{R}(\mathrm{OH})_{2}$

An overall equilibrium constant for the combination of the two reactions was calculated to be $K_{0}=0.960$ (22), and the rate constant for the hydrolysis reaction (21) was detemined as $k=5.71 \times 10^{-3} / \mathrm{Ms}$.

A disturbing inconsistancy between this reaction mechanism and the experimental data which was. not explained was that the rate of loss of optical activity of solutions containing dissolved complex was reported to increase when excess catechol was present (20). 
Following the above publications there appeared a number of studies pertaining only to the structure of the $1: 3 \mathrm{As}(\mathrm{V})$ to catechol complex. Mason and Mason (26) noted that the absorbance spectra of solutions prepared from the solid complex are essentially the same as the spectrum of a catechol solution and the molar absorptivity of the catechol is one third that of the complex. From analysis of the absorbance spectra and circular dichroism by means of a coupled dipole model, they concluded that structure II, Figure I, is correct. As a sidelight they mentioned that an NMR spectrum of the dissolved complex in $D_{2} \mathrm{O}$ showed a closely spaced doublet for the aromatic protons, inconsistent with the structure chosen. They rationalized that while there might possibly be an exchange between the two structures, this would not be consistent with the relatively slow rate of racemization of the complex acid noted by Jones et al. By comparing the circular dichroism and absorbance spectra of the complex acid and complex anion they also concluded that the complex anion is not appreciably protonated at $\mathrm{pH} 1.0$

Ito (27) used $x$-ray diffraction and circular dichroism to come to the same conculsion as to the structure of the solid complex. Utilizing a three dimensional Fourier method coupled with $x$-ray diffraction he was able to determine that the crystalline complex also has a tris chelate structure. His circular dichroism differed slightiy from that presented by Mason and Mason (26) but still indicates that a tris structure is correct.

Wieber and Malion (28) synthesized a number of organo-arsenate molecules in which arsenate is hexacoordinated and contains no water 
molecules in the coordinate sphere. This fact was determined from NMR spectra. Mann (29) has compiled a number of different organoarsenic compounds, among which are examples of bridged arsenites via a catechol molecule.

A group of papers (30-32) was published where the arsenate catechol system was utilized for a solvent extraction procedure. Rais et al. $(30,31)$ found that cesium could be extracted efficiently into nitrobenzene from an acidic media in the presence of the $1: 3$ arsenate-catechol complex. Writing the general reaction.

(3) $\mathrm{H}_{3} \mathrm{AsO}_{4}+\mathrm{nH}_{2} \mathrm{~L}=\mathrm{H}^{+}+\mathrm{AsO}_{3-\mathrm{n}_{\mathrm{n}}}+(\mathrm{n}+1) \mathrm{H}_{2} \mathrm{O}$ where $n=1-3$ and the complex formed may or may not be protonated. They utilized the fact that the titration curves of solutions of $0.005 \mathrm{M} \mathrm{As}(\mathrm{V})$ changes as catechol $(0-0.2 \mathrm{M})$ is added to calculate a formation constant $\beta_{3}^{0}=1400$ for the $1: 3$ species. It appears they were not consistent in the $A s(V)$ species for which they wrote the reaction, and the species they used to calculate the formation constant. AlI their data points to $\mathrm{H}_{2} \mathrm{AsO}_{4}^{-}$as opposed to $\mathrm{H}_{3} \mathrm{AsO}_{4}$ being used in their calculation. This would correspond to a $\beta_{3}=10 \pm 2$ based on $\mathrm{H}_{3} \mathrm{AsO}_{4}$ being the species used in the calculation. These titrations were done in $1 \mathrm{M} \mathrm{NaCl}$ solutions.

They assumed that the uncomplexed catechol concentration was essentially equal to the added catechol concentration. The authors commented that although there is a possibility of three complexes being present their experimental data was apparently reliable only in the region where the 1:3 complex is formed. The point was also brought out that as the concentration of the $A s(V)$ is increased, the formation con- 
stant appears to decrease $\left(\beta_{3}^{-}=680\right.$ when $\left.C_{A S}=0.1 M\right)$. From the titration curves the acid dissociation constant, $\mathrm{K}_{\mathrm{a} 3}$, of the complex was estimated to be between 0.04-0.1.

A number of years later Rais and Krtil (32) estimated from solvent extraction data, that $\beta_{3}^{*}=0.6$ where $\beta^{*}$ is written in tems of a protonated complex and $\mathrm{H}_{3} \mathrm{AsO}_{4}$. Noting the range of $\mathrm{K}_{\mathrm{a}}$ puts $\beta_{3}$ between 6 and 15.

Essentially the same titration experiment done by Rais et al. (31) was recently reported by Votava and Bartusek (33). Titrating 0.037M $\mathrm{KH}_{2} \mathrm{AsO}_{4}$ solutions which had various catechol concentrations (between 0.16 and $0.80 \mathrm{M}$ ) with base they calculated from the shift in the second inflection point that $\beta_{2}=0.041, \beta_{3}=0.054$. They also assumed that the uncomplexed catechol concentration was essentially equal to the concentration added.

Votava and Bartusek also pointed out that redox reactions of the type

$$
\begin{aligned}
& \mathrm{H}_{3} \mathrm{AsO}_{4}+\mathrm{H}_{2} \mathrm{~L}_{1}=\mathrm{H}_{3} \mathrm{AsO}_{3}+\mathrm{L}+\mathrm{H}_{2} \mathrm{O} \\
& \mathrm{H}_{2} \mathrm{AsO}_{4}^{-}+\mathrm{H}_{2} \mathrm{~L}=\mathrm{H}_{3} \mathrm{AsO}_{3}+\mathrm{L}+\mathrm{OH}^{-}
\end{aligned}
$$

are possible, but that oxidation products of catechol would discolor the solution ( $L=q u i n o n e)$ which was not observed, also the reaction of catechol with $\mathrm{H}_{2} \mathrm{AsO}_{4}^{-}$does not involve consumption of a proton.

Summarizing the information about the system to date, it is obvious that As(V) forms a weak complex with catechol. The formation constants determined by the two groups $(31,33)$ mentioned differ by two orders of magnitude. Using this information it seems that Jones et al. 
(21-24) were apparently observing a simple dissociation of the $1: 3$ complex and, although it is not clear from the publications, they probably titrated essentially arsenic acid solutions which were the basis for the $\mathrm{pK}_{\mathrm{a}}$ values reported. Roe (16) observed that the current produced from the reduction of $A s(V)$ in the presence of a large excess of catechol rises to a maximum and decays. The maximum current found by extrapolation was the same at all $\mathrm{pH}^{\prime} \mathrm{s}$ studied $(\mathrm{pH}=0-3)$. The final current and rate of decay between the initial and final current is a function of $\mathrm{pH}$ and catechol concentration. At $\mathrm{pH}=0$ the current was essentially a factor of ten greater than the current at $\mathrm{pH}=2$. The object of this study was to determine the formation constants of any complex present and from these values, along with rate measurements associated with the dissociation of the $1: 3$ complex, identify the species which is polarographically reducible and explain its time concentration behavior. 


\section{MATERIALS AND APPARATUS}

$\mathrm{pH}$ Meter and Accessories:

All $\mathrm{pH}$ measurements were made with a Chemtrix plon Meter Type 50, utilizing the expanded scale for all pH-stat titrations. The electrodes used were a Corning, rugged $\mathrm{pH}$ glass electrode and a double junction reference electrode consisting of a saturated calomel electrode inserted into a glass sleeve containing $1 \mathrm{M} \mathrm{NaCl}$ and in contact with the solution by means of a porous vycor plug. The meter was initially calibrated wi.th standard buffers .

\section{Catechol:}

Baker grade pyrocatechol was used without further purification. The crystals were pure white except for small amounts of black crysta1s, presumibibly oxidized catechol, which could be removed prior to weighing:

Arsenic Acid Solutions:

Arsenic acid solutions were typically prepared by boiling Baker analyzed $\mathrm{As}_{2} \mathrm{O}_{5}$ in distilled water until the solution cleared. This solution was filtered and standardized by potentiometric titration.

\section{Acids and Bases:}

Al1 acids and bases were prepared and standardized in the normal way. Sodium hydroxide and perchloric acid were from Mallinckrodt and were analytical grade. 
Sodium Perchlorate:

The sodium perchlorate used for ionic strength adjustment was prepared by titrating solutions of $\mathrm{NaOH}$ with $\mathrm{HClO}_{4}$.

\section{Preparation of Tris(1,2-dioxybenzenato)Arsenic(V) Pentahydrate:}

The procedure of Mann and Watson (25) was used for the preparation of the solid $1: 3$ complex, $\mathrm{HAs}\left(\mathrm{O}_{2} \mathrm{C}_{6} \mathrm{H}_{4}\right)_{3} 5_{2} \mathrm{O}$. $200 \mathrm{~g}$ of catechol were dissolved into a boiling solution of $80 \mathrm{~g} \mathrm{H}_{3} \mathrm{AsO}_{4}$ in $200 \mathrm{ml} \mathrm{H}_{2} \mathrm{O}$. This solution was stored under a nitrogen atmosphere to avoid oxidation of the contents. After three days large colorless crystals had developed. After a total of ten days the crystals were seperated from the solution and washed with cold $\mathrm{H}_{2} \mathrm{O}$. Because it had been noted that the complex undergoes decomposition easily upon heating the crystals were vacuum dried. NMR spectra showed that there was about six water molecules present for every molecule of complex.

\section{Polarography:}

All polarographic measurements were made with a Sargent Model XV polarograph. Potentials were calibrated with a digital voltmeter. Currents were calibrated utilizing a test resistor in the polarograph. An $\mathrm{H}$-cell was used for the reaction vessel. The reference electrode was a saturated $\mathrm{NaCl}, \mathrm{Hg} / \mathrm{Hg}_{2} \mathrm{Cl}_{2}$ system and was connected to the sample reservoir with a $1 \mathrm{M} \mathrm{NaNO}_{3}$ in $4 \%$ agar salt bridge. Solutions were deoxygenated by bubbling argon through for five minutes. The same capillary and drop time were used for all current measurements. At $E_{d e}$ vs $\operatorname{SCE}(\mathrm{NaC} 1)=-0.4 v, m=8.17 \mathrm{mg} / \mathrm{drop}, t=5.5 \mathrm{sec} / \mathrm{drop}$. 
NMR Spectroscopy:

A11 NMR spectra were run on a Varian EM390 NMR spectrometer equipped with a varible temperature controller. Samples were dissolved in "spec" grade $\mathrm{D}_{2} \mathrm{O}$.

Raman Spectroscopy:

Raman spectra were recorded in a $90^{\circ}$ geometry with a Jarrell-Ash 25-300 spectrophotometer equipped with an ITT FW $130130(\mathrm{~S}-20)$ photomultiplier and photon-counting electronics. A Coherent Radiation MG52 $\mathrm{Ar}-\mathrm{Kr}$ ion laser was used for sample illumination. The exciting wavelength was $514.5 \mathrm{~nm}$ the scan speed $1.2 \mathrm{~cm} / \mathrm{s}$ and the resolution was $8 \mathrm{~cm}^{-1}$. Scans were made between $520-880 \mathrm{~cm}^{-1}$. 


\section{EXPERIMENTAL RESULTS}

Potentiometric Titrations:

As mentioned in the introduction, potentiometric titrations have been used previously $(31,33)$ for formation constant determination. Because of the descrepency between these results and to bring out some additional information, it appeared worthwhile to take another look at this experiment.

One experiment consisted of titrations of solutions of arsenic acid solutions $(0.113 \mathrm{M})$ containing various amounts of catechol. These solutions were allowed to sit for a day before titrating them with $\mathrm{NaOH}$. The titration curves obtained are shown in Figure 2. These curves were not analyzed quantitatively for the amount of $A s(V)$ uncomplexed in a given solution, but will be used to provide general information on the acidic characteristics of the complexes.

Since Jones et al. work $(20-24)$ can be interpeted as a slow dissociation of the $1: 3$ complex, it would be expected that titration curves of solutions prepared from the solid 1:3 complex would vary with time. Figure 3 shows two such titration curves. Curve I was obtained by rapidly titrating immediately after the solid complex had dissolved. Curve II was obtained from a similar sample which was titrated more than twelve hours after the complex was dissolved.

From the $\mathrm{pK}_{\mathrm{a}}$ values of arsenic acid and catechol (arsenic acid, $\mathrm{pK}_{1}=2.22, \mathrm{pK}_{2}=7.00, \mathrm{pK}_{3}=11.5$; catechol, $\mathrm{pK}_{1}=9.3, \mathrm{pK}_{2}=12$ ) the $\mathrm{pH}^{\prime} \mathrm{s}$ which 


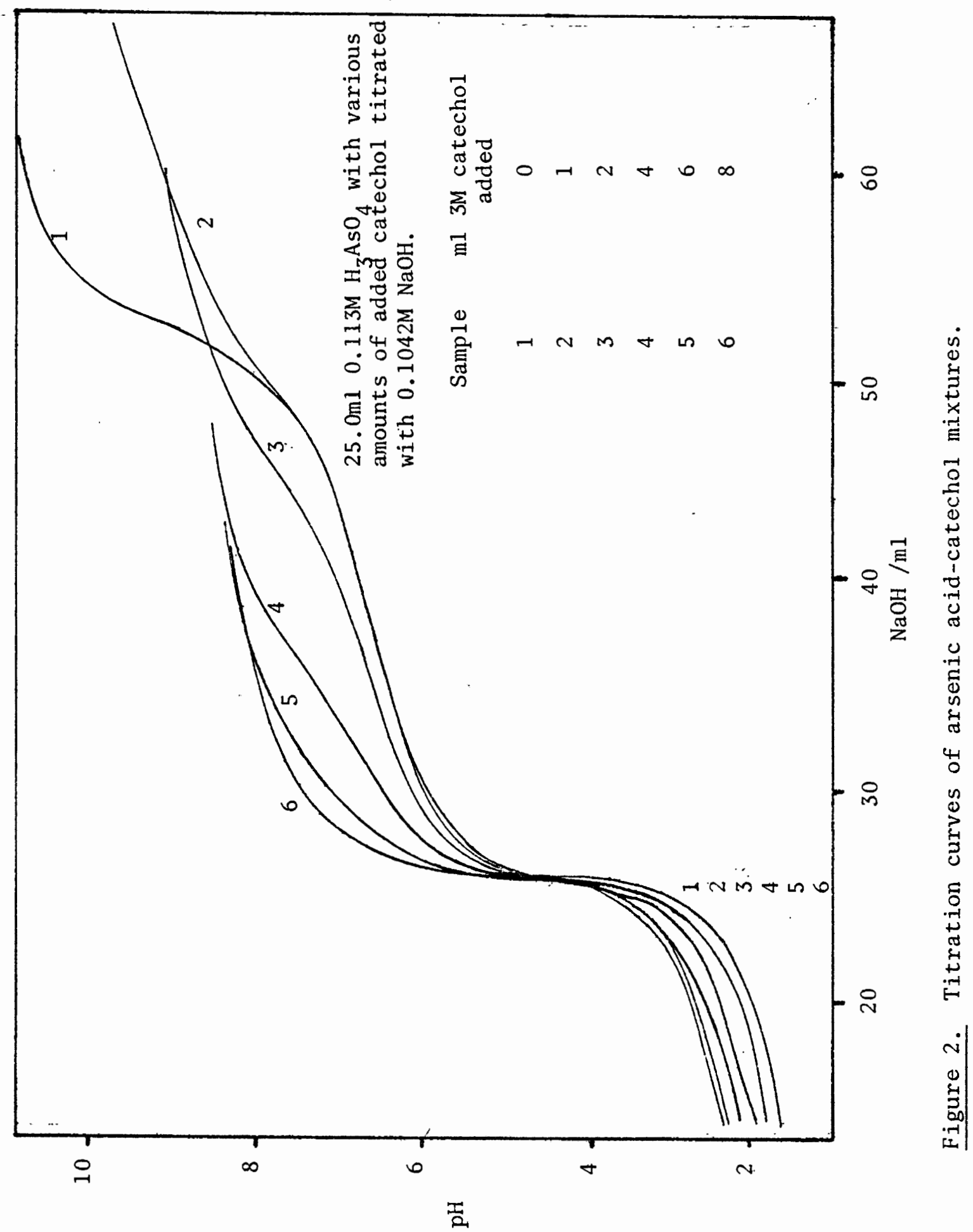




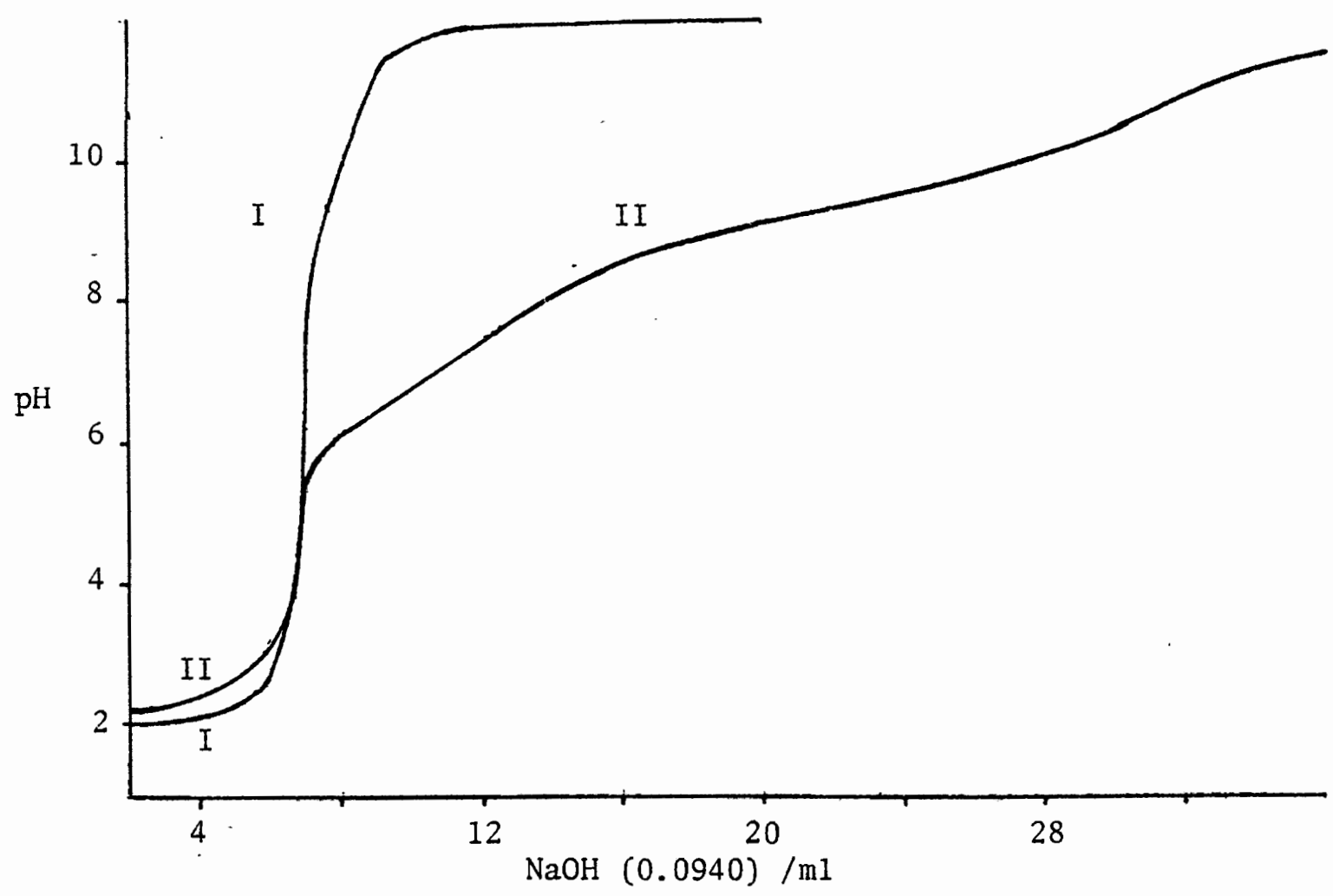

Figure 3. Titration curves of solutions prepared from the $1: 3$ ccmplex. $0.29 \mathrm{~g}$ complex in $25 \mathrm{ml} \mathrm{H} \mathrm{H}_{2} \mathrm{O}$, curve I obtained from immediate titration, curve II from the solution which sat for twelve hours.

should correspond to the inflection points when titrating a mixture containing both should be about $\mathrm{pH}=4.6$ and 9.3 for arsenic acid and $\mathrm{pH}=10.6$ for catechol. The inflection points of curve II, Figure 3 correspond to these. This shows that all of the $1: 3$ complex has dissociated, and that there is 0.64 moles As (V) and $1.8 \mathrm{mmoles}$ of catechol, essentially the $1: 3$ ratio expected. 
Measurements of the Liberation of Protons in the Reaction Between $\mathrm{H}_{3} \mathrm{AsO}_{4}$ and Catechol:

By measuring the number of protons liberated in the reaction between $\mathrm{H}_{3} \mathrm{AsO}_{4}$ and catechol, it should be possible to calculate formation constants and estimate acid dissociation constants for any complexes present. The procedure for this measurement is as follows. An As(V) solution was prepared, typically with a concentration between 0.04-0.01M, and the $\mathrm{pH}$ adjusted to a selected value in the range 1-3. The $\mathrm{pH}$ of catechol solutions $(0.1-2 \mathrm{M})$ was then adjusted to be within $0.002 \mathrm{pH}$ units of that of the As(V) solution. All solutions had an ionic strength $\mathrm{I}=1 \mathrm{M}$ using $\mathrm{NaClO}_{4}$ and $\mathrm{HClO}_{4} \cdot 10.0 \mathrm{ml}$ of the catechol solution was added to $20.0 \mathrm{ml}$ of the As(V) solutions, the resulting mixture sealed and allowed to equilibrate for at least twenty hours. The $\mathrm{pH}$ of these solutions was then checked and readjusted if necessary using $\mathrm{NaOH}$, to the original $\mathrm{pH}$ of the As(V) solution, once again to within $0.002 \mathrm{pH}$ units. The solutions were again sealed and sat for a number of hours at which time the $\mathrm{pH}$ was again checked and adjusted if necessary. This procedure was repeated until there was no longer any perceptible $\mathrm{pH}$ change. Care was taken to choose appropriate concentrations of $\mathrm{NaOH}$ so that there resulted only about a $1 \%$ dilution of the original solution. Much effort was made to insure that $\mathrm{pH}$ readings were correct. There were three blanks used in each run which were simply the $A s(V)$ solution used in the experiment with no catechol added. The $\mathrm{pH}$ meter was recalibrated after each sample. If any drift had occurred the sample $\mathrm{pH}$ would be rechecked and adjusted if necessary. This rather tedious prodedure was necessary as there were drift problems associated with leaving the electrodes immersed in the catechol 
solution.

A slight variation in the procedure was used for one run, at $\mathrm{pH}=1.71$, where solid catechol instead of a solution was added to the As(V) solution. By a very nonrigorous determination of the partial molar volume $\left(10.0 \mathrm{ml} \mathrm{H}{ }^{0+1 g}\right.$ catechol equals $10.7 \mathrm{ml}$ solution) corrections for the actual volume were made and were quite small for the case where the catechol concentration is between $0.05-0.2 \mathrm{M}$. This procedure was utilized because of its simplicity and was found to yield results consistent with the other runs.

From the polarography data (16) reported, it was apparent that at least two species of complex are present so that the simultaneous presence of $1: 1,1: 2$, and $1: 3$ As $(\mathrm{V}):$ catechol complexes must be considered. In the $\mathrm{pH}$ range $1-3$ the two uncomplexed forms of $\mathrm{As}(\mathrm{V})$ are $\mathrm{H}_{3} \mathrm{AsO}_{4}$ and $\mathrm{H}_{2} \mathrm{AsO}_{4}^{-}$. From a mass balance equation for As $(\mathrm{V})$ considering all the possible equilibria the following equation can be derived (see Appen$\mathrm{dix}$.

$$
\begin{aligned}
& \mathrm{C}_{\mathrm{As}}\left(\mathrm{H}^{+}\right) /\left(\mathrm{H}_{3} \mathrm{AsO}_{4}\right)=\left(\mathrm{H}_{2} \mathrm{~L}\right)\left\{\mathrm{B}_{1}+\mathrm{B}_{1}\left(\mathrm{H}^{+}\right) / \mathrm{K}_{\mathrm{al}}\right\}+\left(\mathrm{H}_{2} \mathrm{~L}\right)^{2}\left\{\mathrm{~B}_{2}+\mathrm{B}_{2}\left(\mathrm{H}^{+}\right) / \mathrm{K}_{2}{ }^{+}\right. \\
& \qquad\left(\mathrm{H}_{2} \mathrm{~L}\right)^{3}\left\{\mathrm{~B}_{3}+\mathrm{B}_{3}\left(\mathrm{H}^{+}\right) / \mathrm{K}_{\mathrm{a} 3}\right\}+\left(\mathrm{H}^{+}\right)+\mathrm{K}_{1} \\
& \mathrm{n}=1-3 \\
& \mathrm{~B}_{\mathrm{n}}=\text { overal1 formation constant of any complex present } \\
& \mathrm{K}_{\text {an }}=\text { acid dissociation constant of any complex present } \\
& \mathrm{K}_{1}=\text { Iirst acid dissociation constant of arsenic acid }=0.0088 \\
& \quad \text { in } 1 \mathrm{M} \text { NaC10 } 4
\end{aligned}
$$

Methods for calculation of uncomplexed $\mathrm{II}_{3} \mathrm{AsO}_{4}$ and catechol $\left(\mathrm{H}_{2} \mathrm{~L}\right)$ concentrations are presented in the Appendix. From equation (1) it can be 
seen that if the uncomplexed catechol concentration, $\left(\mathrm{H}_{2} \mathrm{~L}\right)$, is approximately equal to the concentration added, $\mathrm{C}_{\mathrm{H}_{2}} \mathrm{~L}$, and if it is assumed that for each proton liberated one $\mathrm{H}_{3} \mathrm{AsO}_{4}$ is complexed the calculation is quite straightforeward. Using a minumum of two runs at different $\mathrm{pH}^{\prime} \mathrm{s}$, the results could be fit to a third order polynomial. Comparing the coefficients obtained would yield both $\beta^{\prime} s$ and $K_{a}$ 's and the intercept of each curve shoula agree with the sum $\left(\mathrm{H}^{+}\right)+\mathrm{K}_{1}$ as seen in equation (1). Unfortunately in order to get a resolvable $\mathrm{pH}$ change the As (V) concentration must be relatively high and therefore $\mathrm{C}_{\mathrm{H}_{2}} \mathrm{~L} \neq\left(\mathrm{H}_{2} \mathrm{~L}\right)$. In a situation such as this, when more than one complex must be assumed, an iterative technique is used for calculation of the uncomplexed ligand. It was found that it was not possible to simply do a third order polynomial fit on. the experimental data. The regression method appears to be very sensitive to precisions of experimental data. In almost every case some negative coefficients were obtained, corresponding to negative formation constants.

It appeared that in order to evaluate the formation constants another procedure must be used. The method decided upon consists of guessing initial values of $\beta$ to allow the uncomplexed catechol concentration to be calculated, then using equation (1) to calculate the uncomplexed $\mathrm{H}_{3} \mathrm{AsO}_{4}$ concentration, which is known experimentally from the number moles of protons liberated, and comparing the experimental and calculated values, By choosing $\beta^{\prime}$ s so there appeared to be no systenatic deviation between the calculated and experimental $\mathrm{H}_{3} \mathrm{AsO}_{4}$ concentration it was found that $\beta_{3}=6.5-9, \beta_{2} \approx 0.02$ and $\beta_{1} \approx 0.01$. It was also found that there was no systematic increase in these values as the $\mathrm{pH}$ 
decreased, which is predicted from equation (I) if $\mathrm{pk}_{\mathrm{a}}>\mathrm{pH}$. (In essence the second term inside the parenthesis in equation ( 1 ) has been omitted for these estimations.) This means that apparently at least the predominant $1: 3$ complex has a $\mathrm{pK}_{\mathrm{a}}<1$. Between runs there was a systematic deviation which is probably associated with the uncertainty of knowing the absolute $\mathrm{pH}$ which is very important in the calculation.

In order to compare the results between runs and get an estimate of how well the $\beta^{\prime} s$ are known, equation (I) was rearranged slightly to yield a linear expression.

(2) $Y=\left\{\mathrm{C}_{\mathrm{AS}}\left(\mathrm{H}^{+}\right) /\left(\mathrm{H}_{3} \mathrm{AsO}_{4}\right) \cdot-\mathrm{K}_{1}-\left(\mathrm{H}^{+}\right)-\beta_{1}\left(\mathrm{H}_{2} \mathrm{~L}\right)\right\} /\left(\mathrm{H}_{2} \mathrm{~L}\right){ }^{2}=\beta_{2}+\beta_{3}\left(\mathrm{H}_{2} \mathrm{~L}\right)$

Figure 4 shows the results of a plot of the experimental data gathered at three pH's. Figure 5 shows the results from two of those pH's and obviously gives a much better fit. These curves do show that the estimations of B's made previously were very nearly correct, although $\beta_{1}$ and $\beta_{2}$ must be regarded as only estimates as they are so small and there was much experimental error (as seen at the beginning of the curves in Figures 4 and 5) in the area where these complexes are present.

Using the values $\beta_{1}=0.01, \beta_{2}=0.02$ and $\beta_{3}=7.5$ it is possible to calculate the fraction of each species at a given $\mathrm{pH}$ and catechol concentration. Table $I$ and Table II contain a short summary of these values at $\mathrm{pH} 1$ and 2. Figures 19 and 20 in the Appendix show the entire distribution curves arising from these values at pH 1 and 2 . 


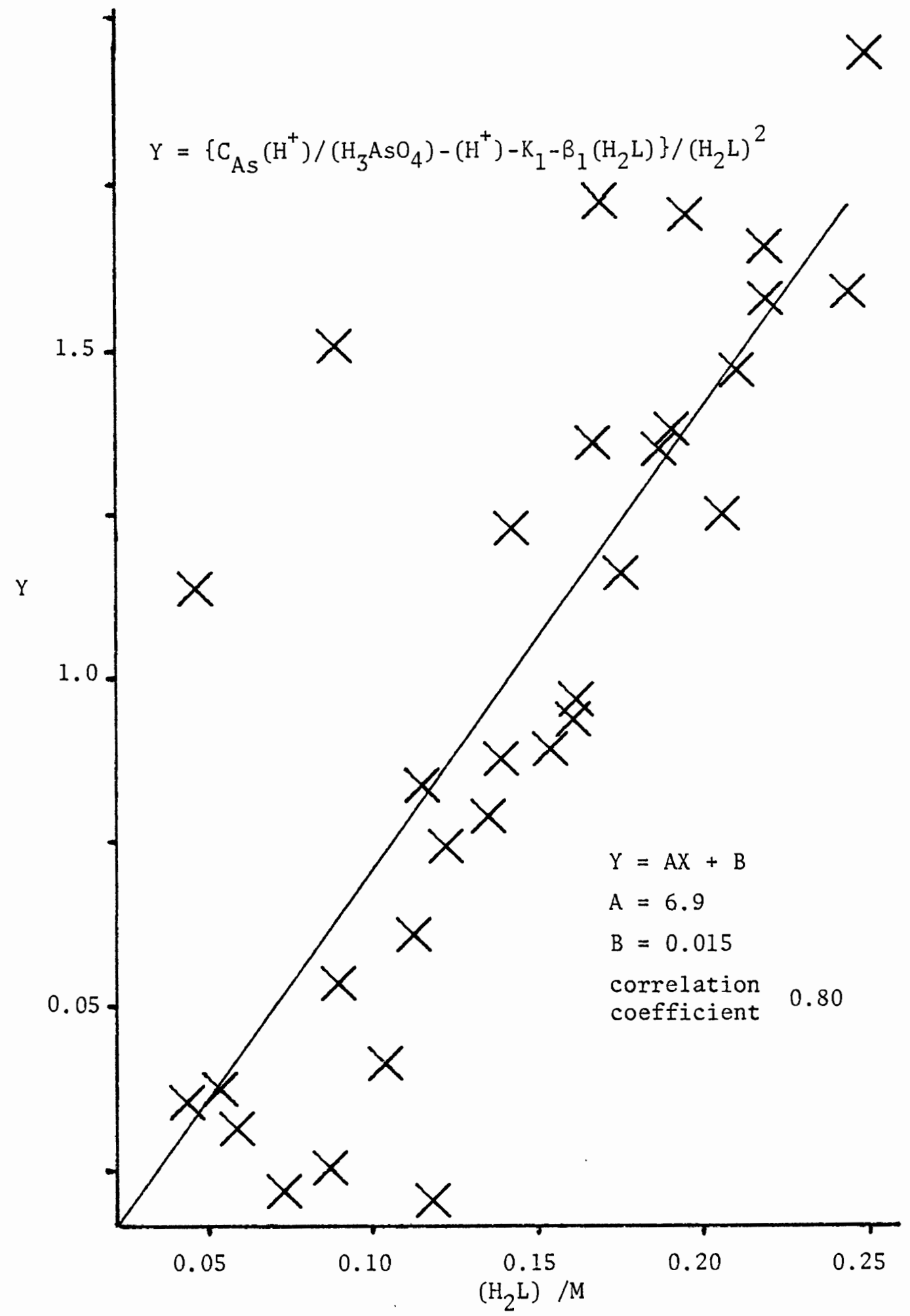

Figure 4. Evaluation of formation constants assuming $\beta_{1}$. Data

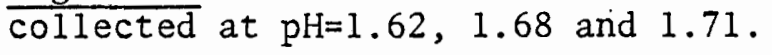




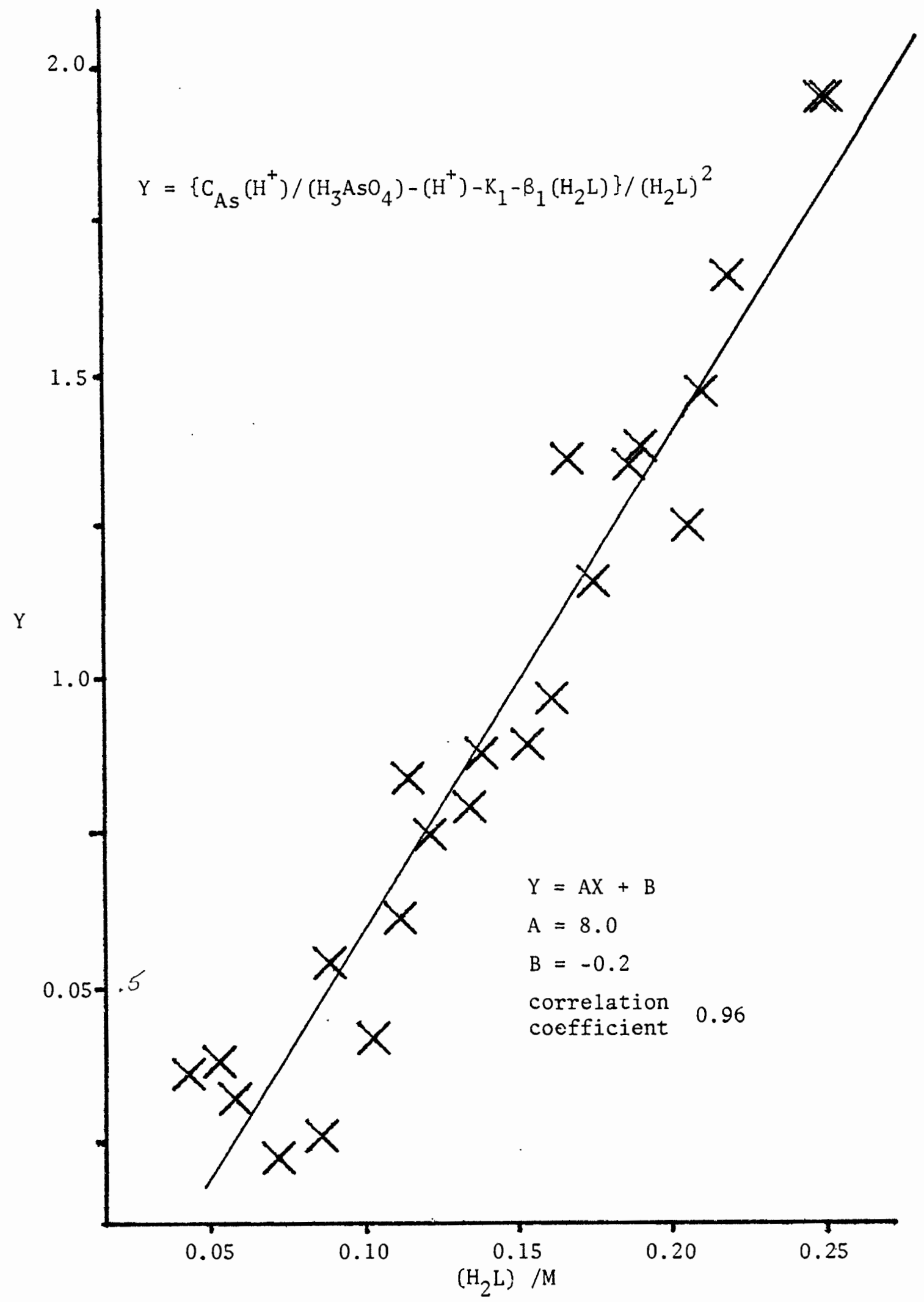

Figure 5. Evaluation of formation constants assuming $\beta_{1}$. Data

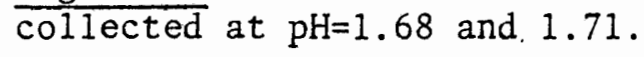




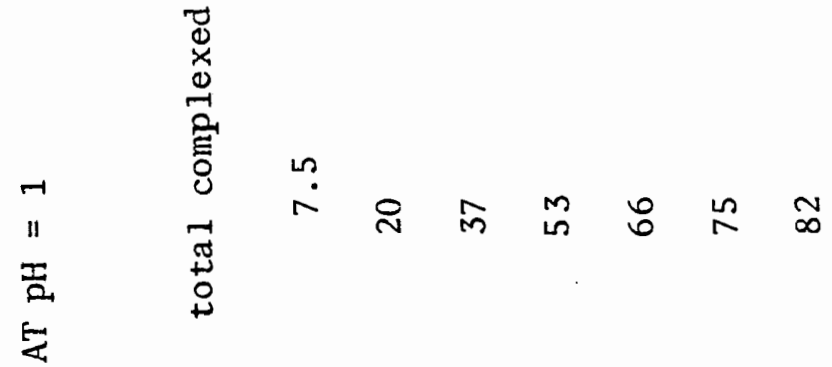

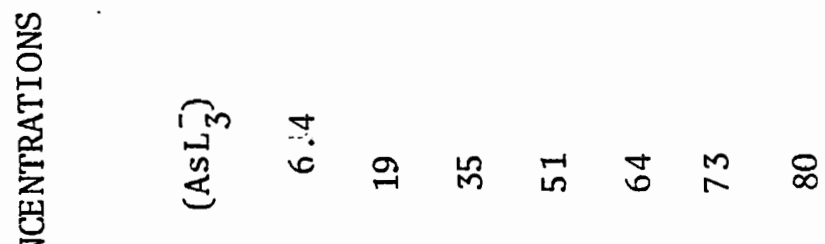

$$
\begin{aligned}
& \text { ○ } \\
& \text { • }
\end{aligned}
$$

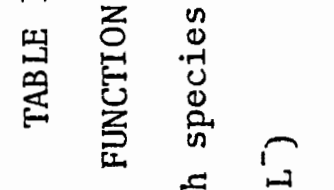

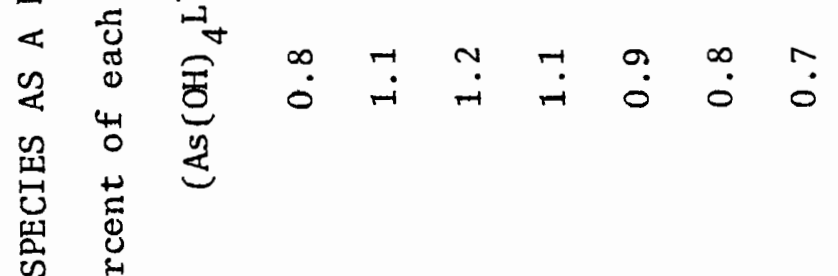

$$
\begin{aligned}
& \text { 部 } \\
& \text { 严 }
\end{aligned}
$$

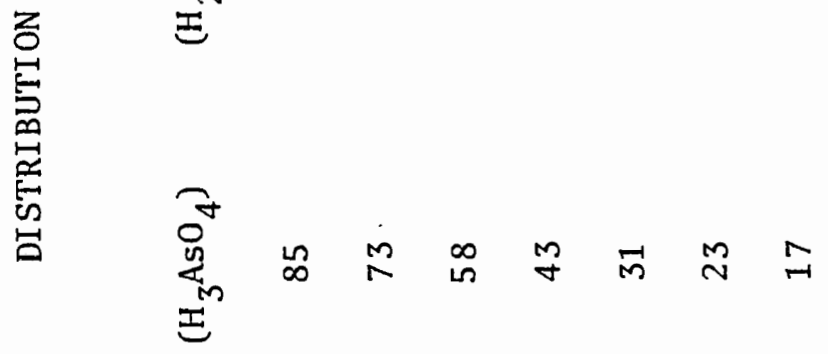

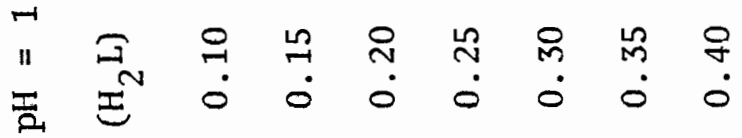




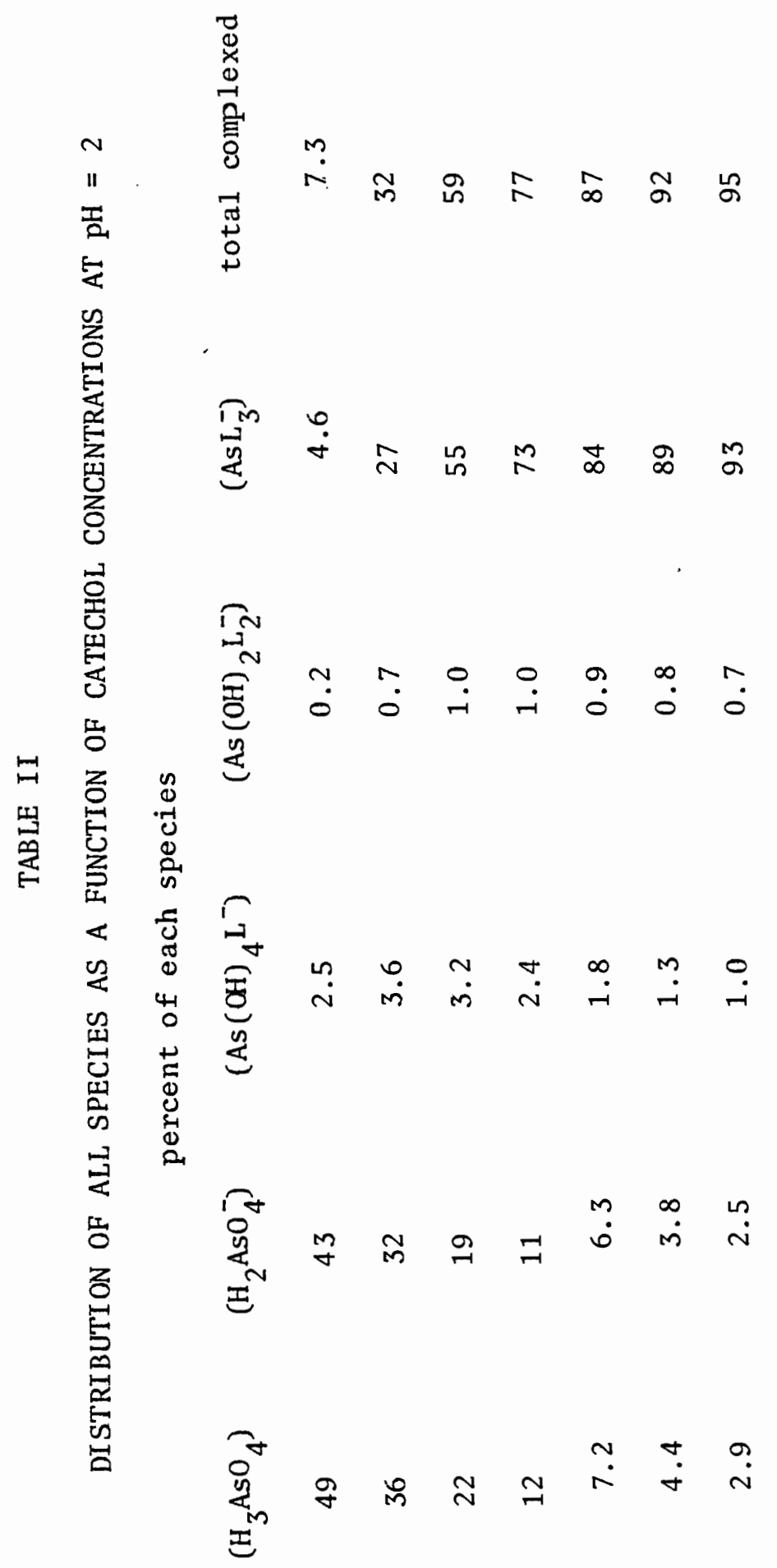

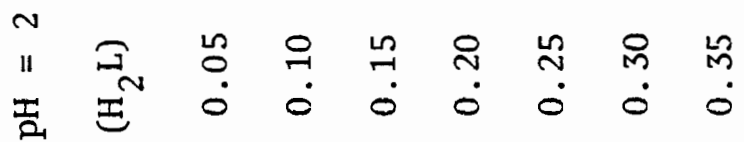


Temperature Study of the NMR Spectra of the 1:3 Complex:

The object of this study was to carry the experiments of Mason and Mason (26) one step further by investigating any possible changes in the NMR of the $1: 3$ complex with changing temperature.

By preparing an approximately $1 \mathrm{M}$ solution from solid $1: 3$ complex the value for $\beta_{3}$ insures that almost all the $A s(V)$ will remain complexed. This solution sat four days before the temperature study was done. Figures 6,7 and 8 . show the NMR spectra for catechol done at room temperature $\left(25^{\circ} \mathrm{C}\right)$ and the $1: 3$ complex at room temperature and $10^{\circ} \mathrm{C}$.

Integration of the peaks in the catechol spectrum indicate a very small amount of $\mathrm{H}_{2} \mathrm{O}$ contamination. Integration of the $1: 3$ complex spectrum indicates that there were about equal amounts of water protons and aromatic protons ie. six waters for each complex ion.

Looking at the types of aromatic protons present in these three spectra yields some interesting observations. The catechol spectrum shows that there are two types of aromatic protons, which is also the case for the $1: 3$ complex at room temperature. When the temperature was lowered to $10^{\circ} \mathrm{C}$ though it is seen that there is now only one type of aromatic proton present in the spectrum of the $1: 3$ complex.

Raman Spectra of As (V) Catechol Solutions:

Raman spectra were taken of several solutions having different As (V) to catechol ratios. The solutions were prepared in $1 \mathrm{M} \mathrm{HClO}_{4}$ for all but the solution which contained only catechol, which was in $0.1 \mathrm{M} \mathrm{HClO}_{4}$. A summary of the peak locations and intensities which could be attributed to catechol or complex formation is given in Table III. Figures 9 and 10 show the spectra of a solution of catechol with- 


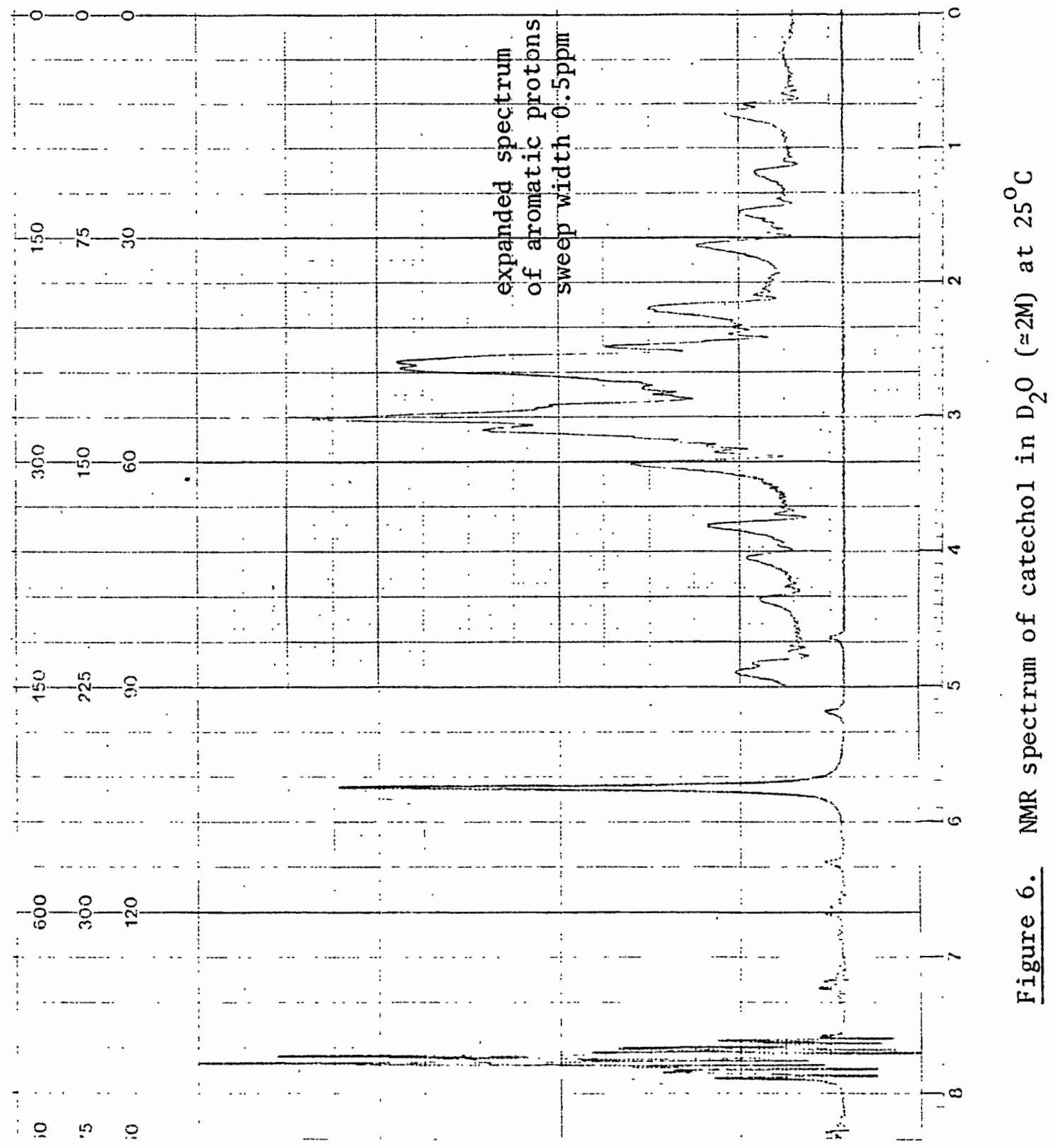




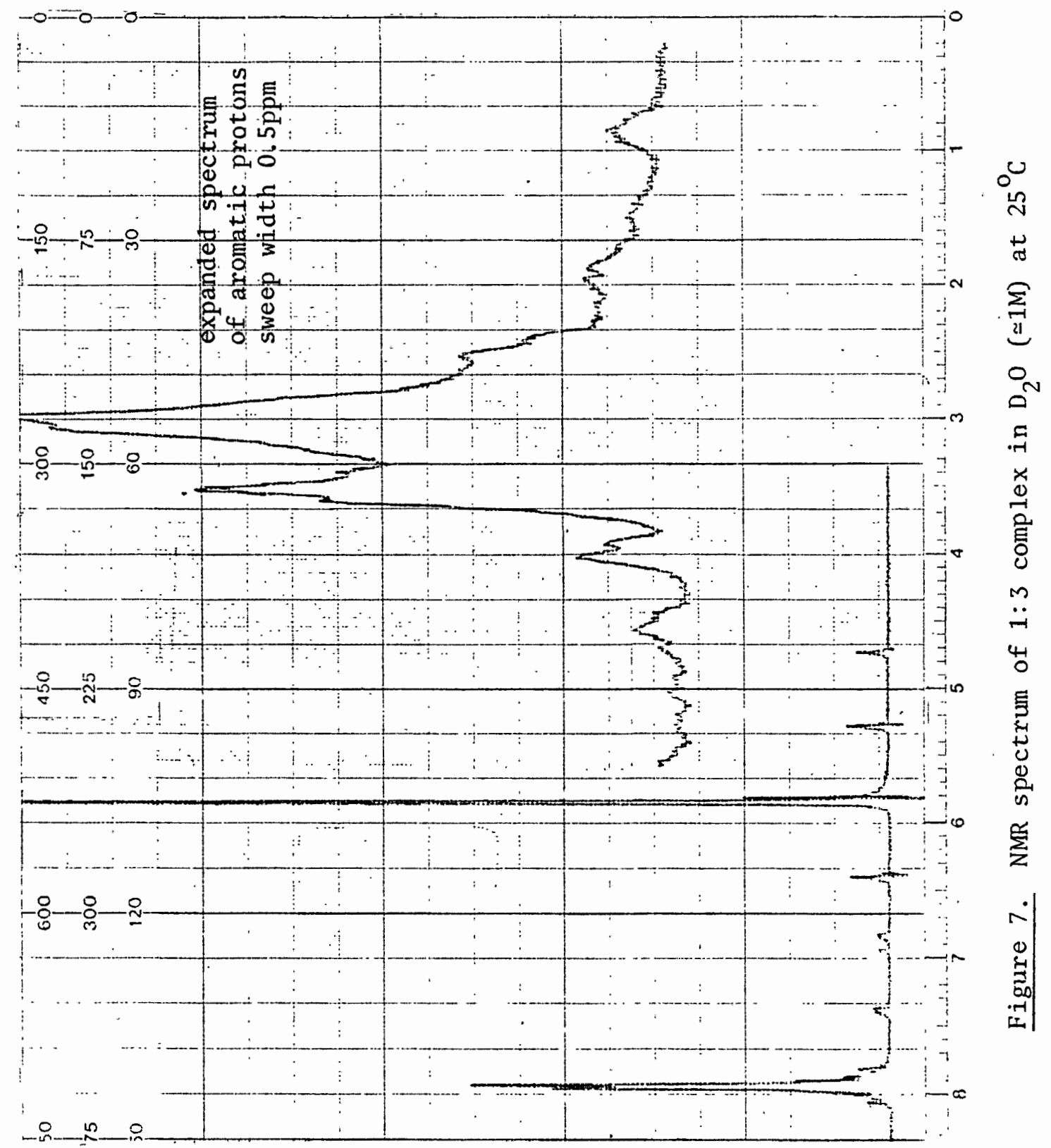




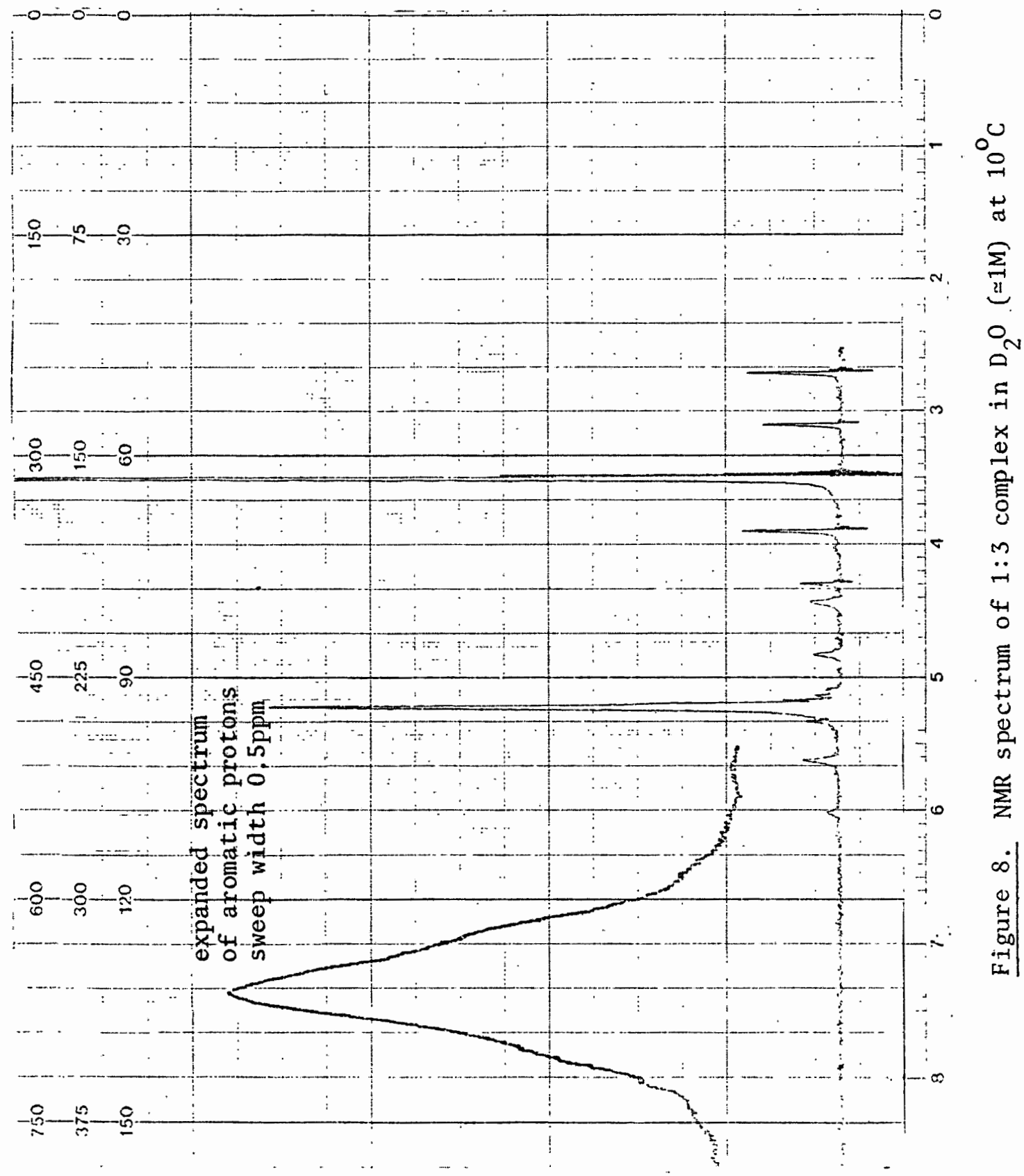


out and with arsenate, respectively.

No attempt was made to rigorously interpet the spectra obtained or predict what pattern of peaks would be expected from the types and amounts of complexes that might be present under the given conditions. Since there appeared a need for spectral information this experiment was undertaken to determine the feasibility of using Raman spectroscopy for elucidation of the structure of any complex present as well as another method to :estimate formation constants.

It was found that the best conditions for observing the development of peaks due to complex formation is $>0.2 \mathrm{M}$ catechol and $0.1 \mathrm{M} \mathrm{As}(\mathrm{V})$. Mixtures which were only $0.01 \mathrm{M}$ in $\mathrm{As}(\mathrm{V})$ showed very little difference from those with catechol alone. The magnitude of the absorptions due to apparent complex fromation as a function of catechol concentration appears to be in at least qualitative agreement with the $\mathrm{pH}$ measurements. Since peak intensity is directly proportional to the concentration of the absorbing species, the spectrum of the $0.5 \mathrm{M}$ catechol solution can be compared with that of the solution containing $0.1 \mathrm{M}$ As (V) and $0.7 \mathrm{M}$ catechol. Comparing the spectra at 1275,1032 and $580 \mathrm{~cm}^{-1}$ and assuming these absorption peaks are characteristic of uncomplexed catechol, it appears that the concentration of uncomplexed catechol in the solution containing $A s(V)$ is about $0.5 \mathrm{M}$. Noting the predominance of the $1: 3$ species and estimating that $\mathrm{pH} \simeq 0.2$ yields $\beta_{3} \simeq 10$, very close to the value obtained potentiometrically. 


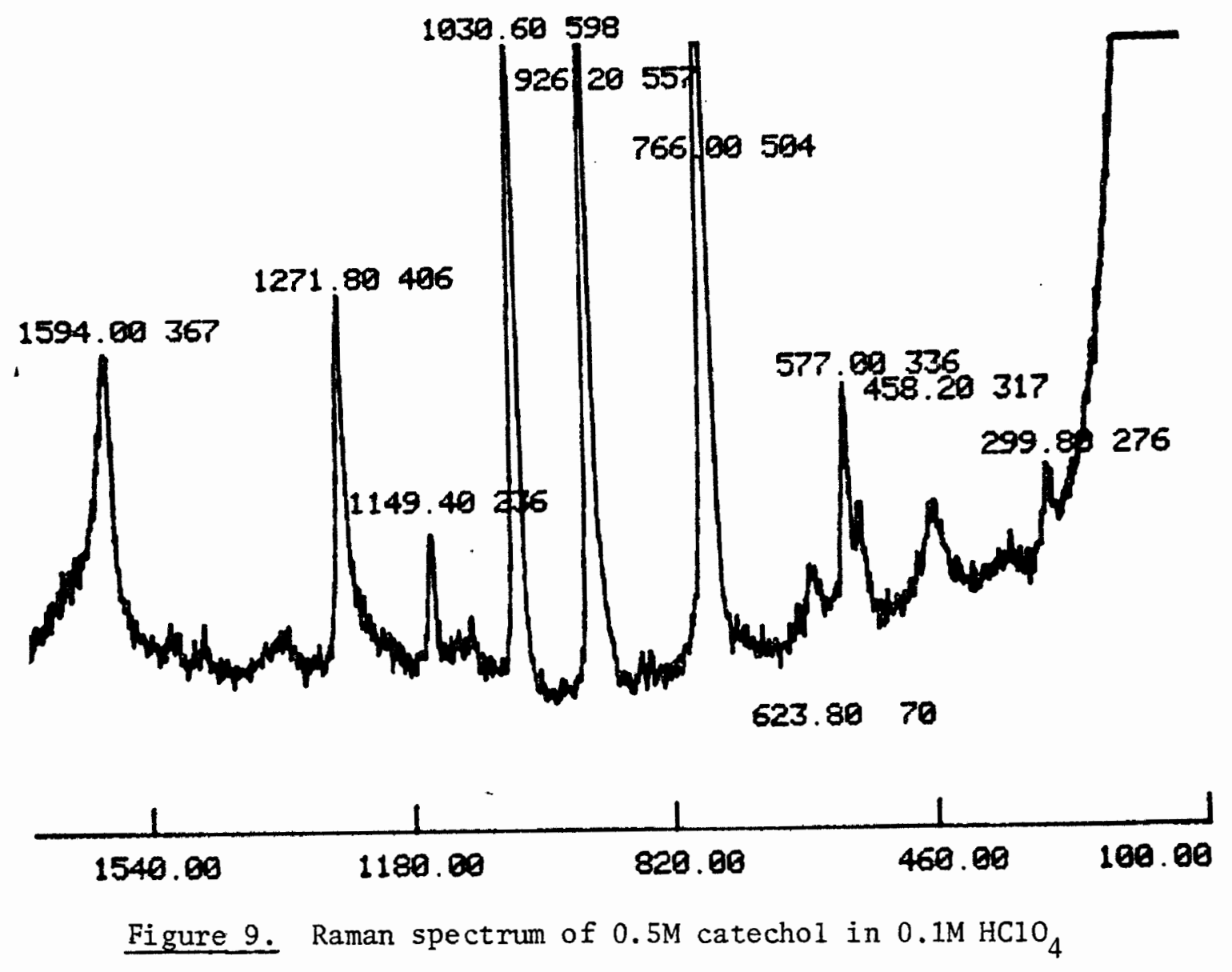




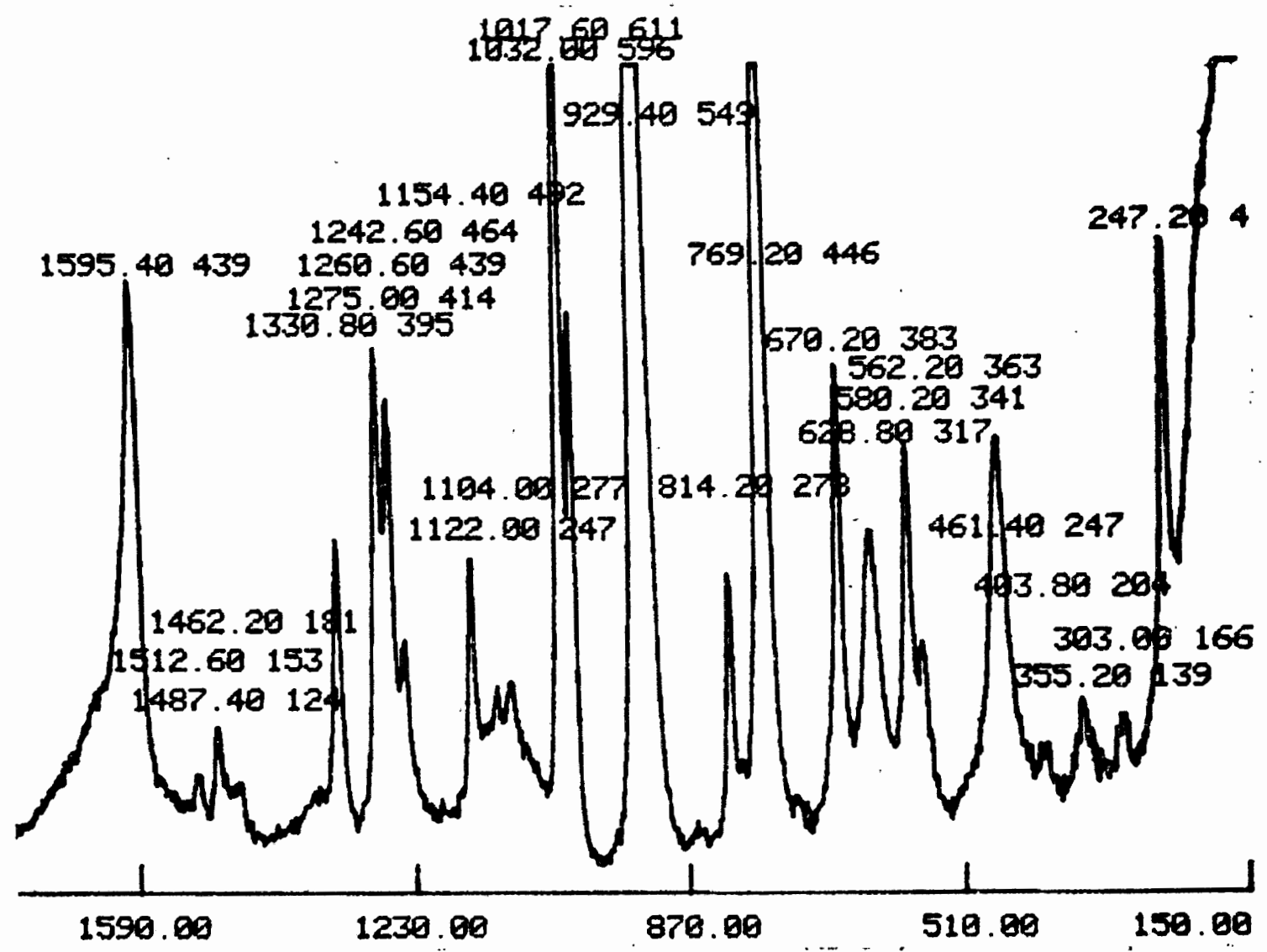

Figure 10. Raman spectrum of solution containing 0.1M As(V), $0.7 \mathrm{M}$ catechol and $1 \mathrm{M} \mathrm{HClO}_{4}$. 


\section{TABLE III}

\section{SUMMARY OF RAMAN PEAKS DUE TO COMPLEX FORMATIONS \\ OR FREE CATECHOL}

As $(\mathrm{V})$ : Cate chol (M)

\begin{tabular}{|c|c|c|c|}
\hline \multicolumn{3}{|c|}{ As (V): Cate chol (M) } & Catecho1 \\
\hline $0.1: 0.7$ & $0.1: 0.2$ & $0.1: 0.1$ & 0.5 \\
\hline $\mathrm{cm}^{-1} \begin{array}{l}\text { relative } \\
\text { intensity }\end{array}$ & $\begin{array}{cl}\mathrm{cm}^{-1} & \text { relative } \\
& \text { intensity }\end{array}$ & $\begin{array}{ll}\mathrm{cm}^{-1} & \begin{array}{l}\text { relative } \\
\text { intensity }\end{array}\end{array}$ & $\begin{array}{cl}\mathrm{cm}^{-1} & \text { relative } \\
& \text { intensity }\end{array}$ \\
\hline$(439)$ & $\overline{1594}-(222)$ & $(14.7)$ & $(367)$ \\
\hline
\end{tabular}

1513 (153)

1487 (124)

1462 (181)

$1331 \quad(395) \quad x$

$\begin{array}{llllllll} & 1275 & (414) & 1275 & (167) & 1275 & (95) & 1272\end{array}$

1261 (439) $\mathrm{X}$

1243 (464) $\mathrm{X}$

1154 (492) $\mathrm{X}$

1149 (236)

1122 (247) $\mathrm{x}$

1104 (277) $\quad \mathrm{X}$

$\begin{array}{llllllll}1032 & (596) & 1032 & (310) & 1032 & (186) & 1031 & \text { (598) }\end{array}$

1018 (611)

860

$814 \quad(278) \quad X$

$\begin{array}{llllllll}769 & (446) & 766 & (579) & 766 & (308) & 766 & (504)\end{array}$

670 (383) $\mathrm{X}$

$\begin{array}{llllllll}580 & (341) & 580 & (146) & 578 & \text { (127) } & 577 & \text { (336) }\end{array}$

562 (363) X

404 (204)

355 (139) $X$

$303(166) \quad X$

$300 \quad(206)$

247 (400) X

$X$ - peak present but small and poorly resolved 
Polarography of As (V)-Catechol Complexes:

The object of this experiment was to observe the magnitude of the limiting current, arising from the reduction of some As(V)-catechol species, as a function of $\mathrm{pH}$ and catechol concentration. Correlating this information with distribution curves for the system, as in Figures 19 and 20, should show which species is electroactive under these conditions. Polarograms were run on solutions used in the experiment described previously (pg.17 to 24). This insured constant pH conditions. Figures 11 and 12 show two polarograms typical of those obtained. The leading edge (around $-0.2 v$ ) of the initial wave changes appearance at different catechol concentrations. The general shape of the wave, though, was the same for all solutions studied, prepared in this manner. A plot of the limiting current of the first wave (about $E_{\mathrm{de}}$ vs. $\operatorname{SCE}(\mathrm{NaCl})=-0.4 \mathrm{v})$ vs. catechol concentration is found in Figure 13.

In order to understand whether the limiting current is diffusion, adsorption or kinetically controlled, the effect of mercury height on current was investigated. Figure 14 shows the results of plotting $i$ vs. $\mathrm{h}^{\frac{1}{2}}$ for the solutions listed. Noting that no dependence of the limiting current on mercury height is indicitive of a kinetic process it might be inferred that a decrease in slope of the lines shows increasing kinetic control. It can then be observed from comparison of the conditions under which each plot was made, that decreasing the $\mathrm{pH}$ increases the kinetic effect, particularily as the pH gets below 1.5. Also, when the catechol concentration is high (above $0.3 \mathrm{M}$ ) the kinetic effect is decreased. 


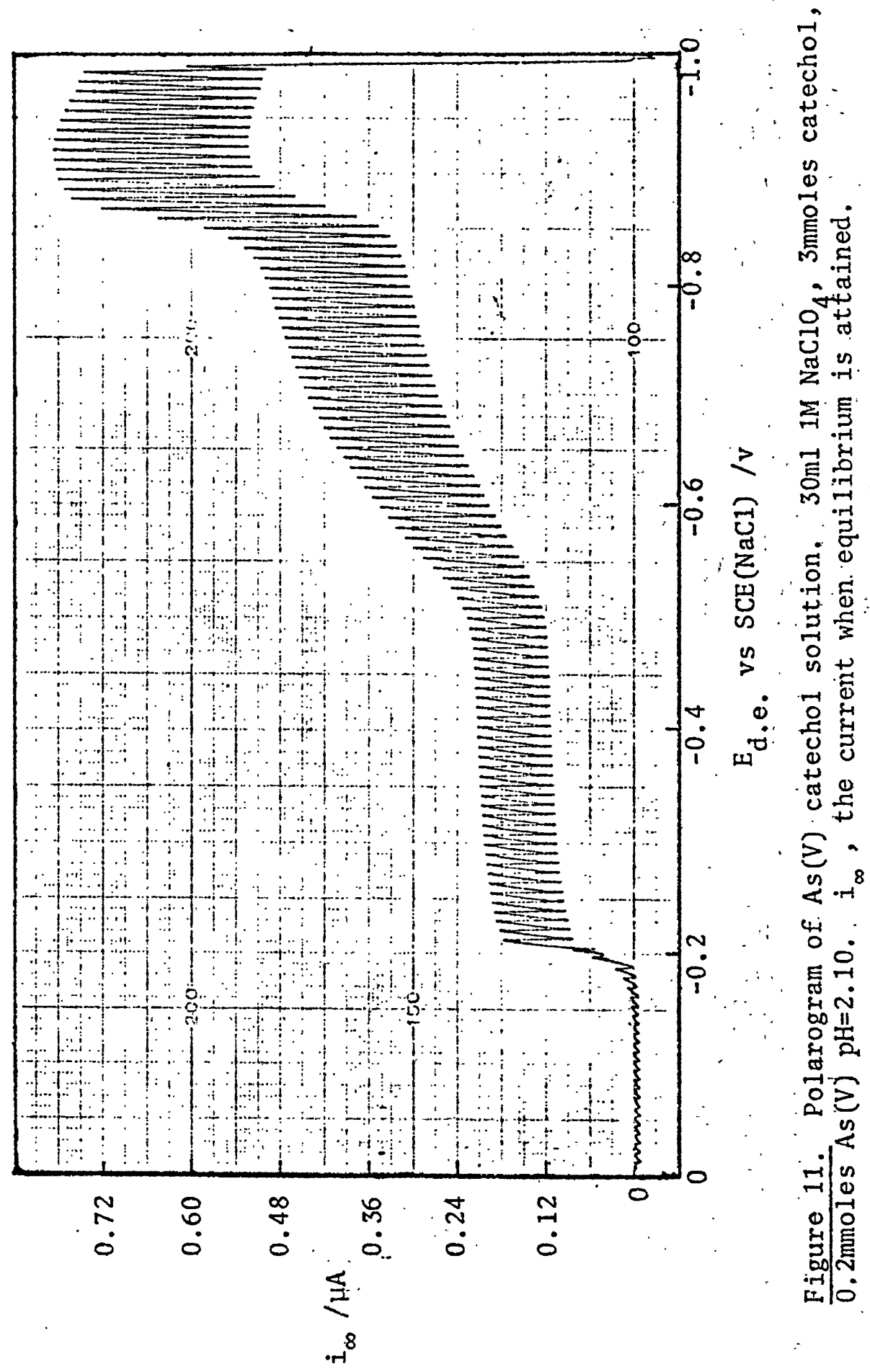




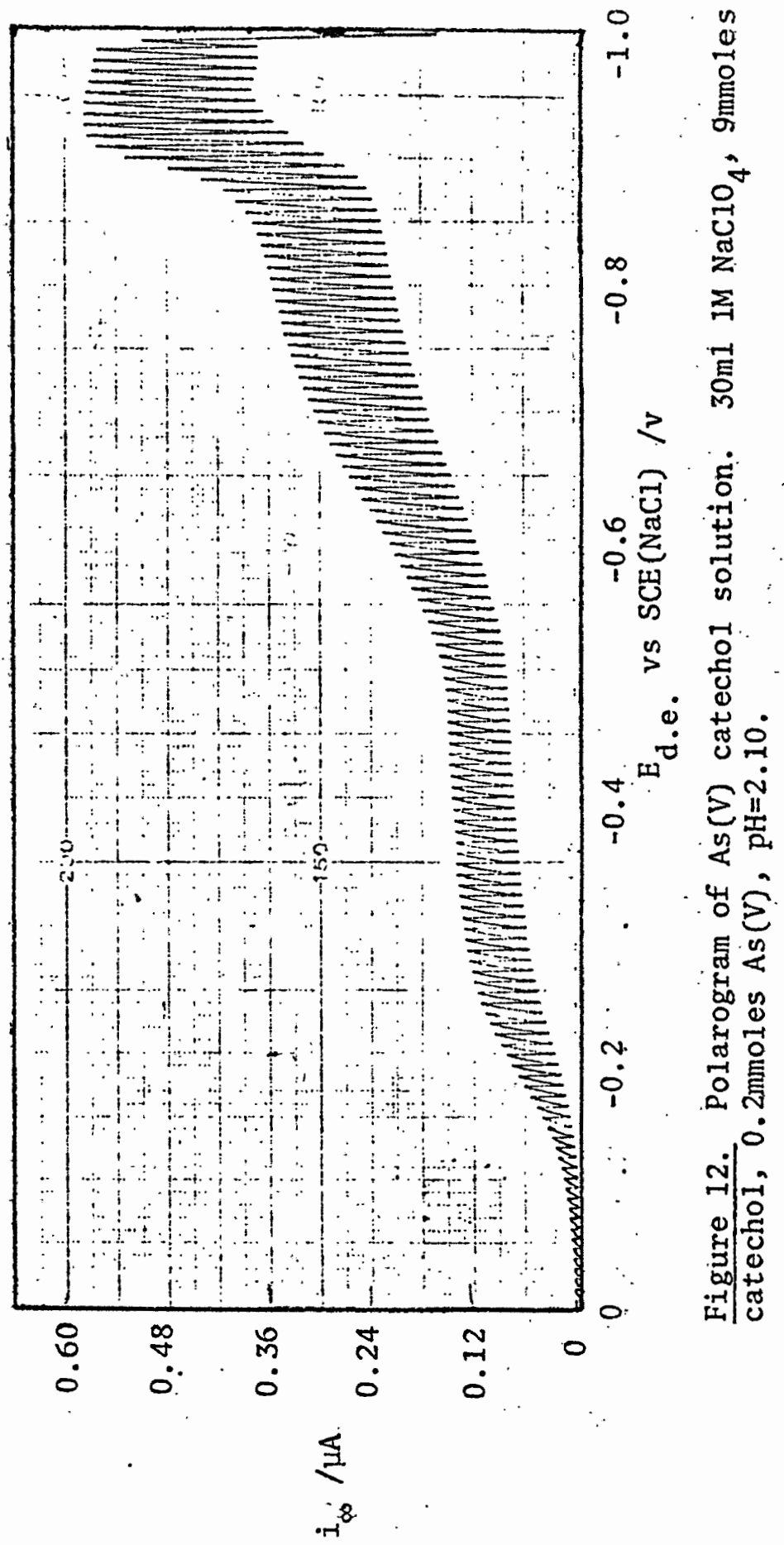




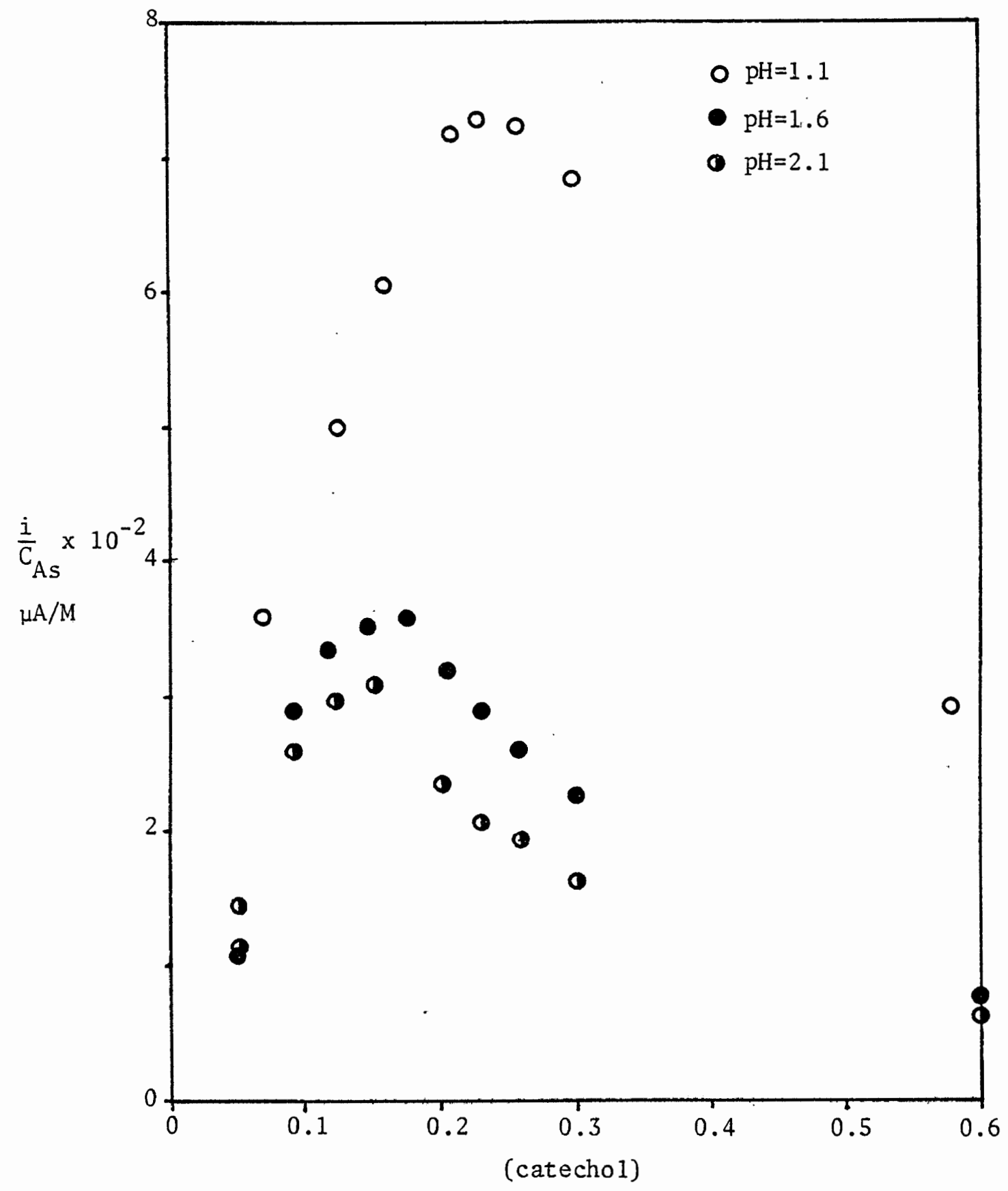

Figure 13. Dependence of the limiting current on $\mathrm{pH}$ and catechol concentration. 


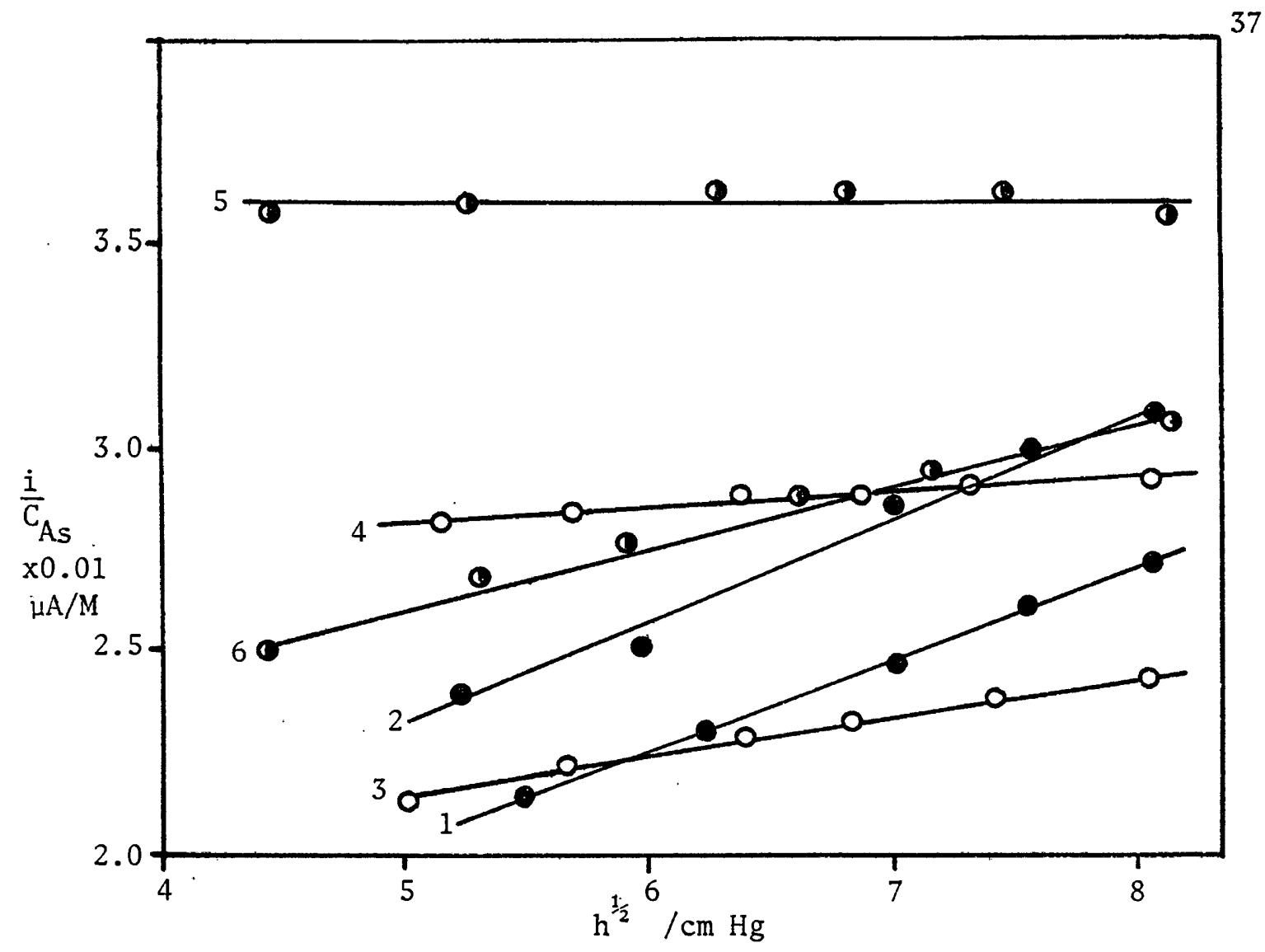

$\begin{array}{lcccccc}\# & \begin{array}{c}\text { As }(\mathrm{V}) \\ \text { (mmoles) }\end{array} & \begin{array}{c}\text { catechol } \\ \text { (mmoles) }\end{array} & \mathrm{pH} & \text { intercept } & \text { slope } & \begin{array}{c}\text { correlation } \\ \text { coefficient }\end{array} \\ 1 & 0.20 & 6.0 & 2.10 & 0.93 & 0.221 & 1.000 \\ 2 & 0.20 & 3.0 & 2.10 & 1.00 & 0.261 & 0.994 \\ 3 & 0.60 & 10.0 & 1.62 & 1.62 & 0.101 & 0.996 \\ 4 & 0.60 & 3.0 & 1.62 & 2.63 & 0.036 & 0.988 \\ 5 & 1.00 & 3.0 & 1.10 & 3.57 & 0.005 & 0.232 \\ 6 & 1.00 & 20.0 & 1.10 & 1.84 & 0.153 & 0.993\end{array}$

Figure 14. Effect of mercury height on current. 


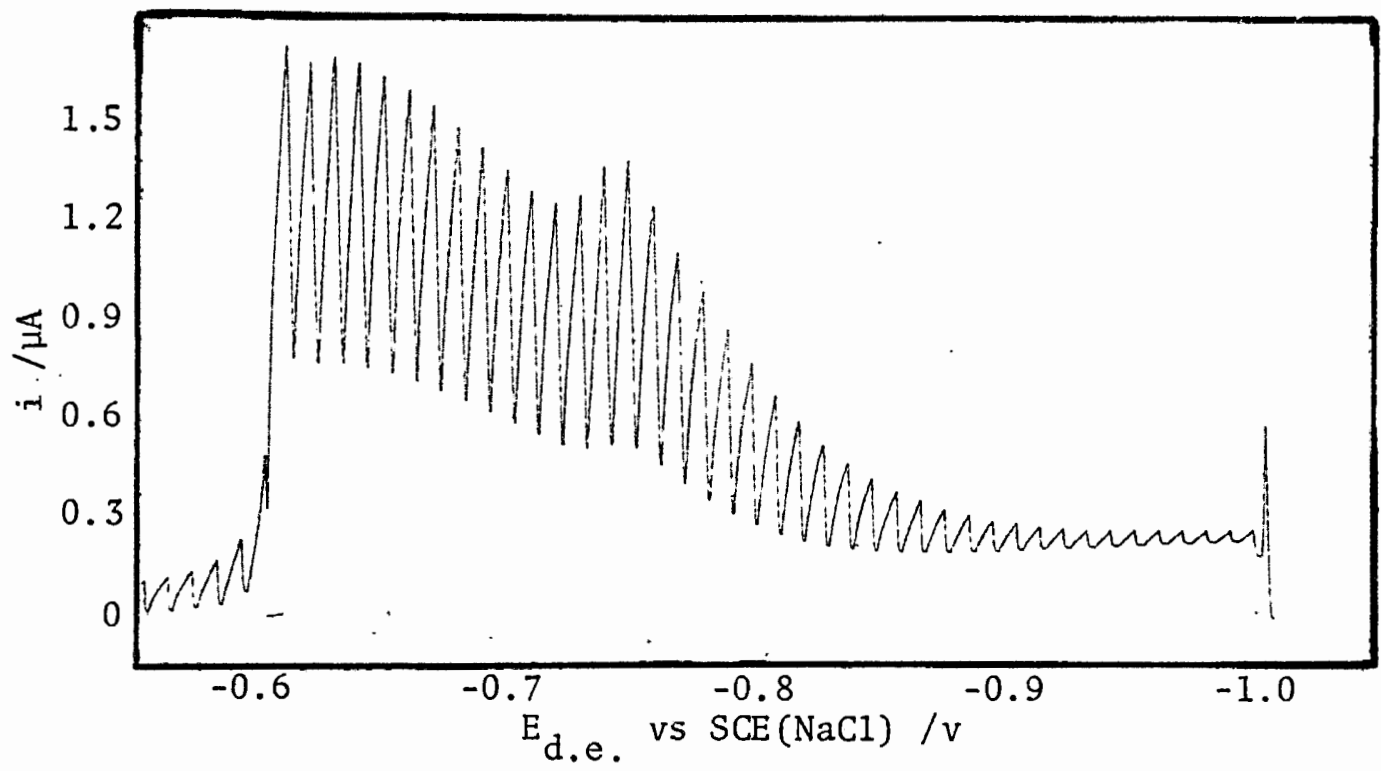

Figure 15. Polarogram of solution containing $0.012 \mathrm{~g} 1: 3$ complex $0.25 \mathrm{ml} \mathrm{IM} \mathrm{HClO}$ and $25 \mathrm{ml} .1 \mathrm{M} \mathrm{NaClO}_{4}$. Scan $(0$ to $-\mathrm{lv})$ began three minutes after dissolution and took a total of ten minutes.

It was found that upon dissolution of solid $1: 3$ complex in $1 \mathrm{M}$ $\mathrm{NaClO}_{4}$ a reduction wave was obtainable, Figure 15. This wave was initially at a maximum and decayed with time disappearing completely when a $10^{-3} \mathrm{M}$ solution with respect to complex was used. The rate of decay appeared to be a function of $\mathrm{pH}$ and the magnitude a function of $\mathrm{pH}$ and catechol concentration as well as initial complex concentration. It was also found that a similar wave could be obtained by injecting $70 \mu \mathrm{I}$ of a solution containing $1 \mathrm{M}$ catecho 1 and $0.05 \mathrm{M}$ As(V) into $25 \mathrm{~m} 1$ $\mathrm{NaClO}_{4} \cdot$ This indicated the wave was not due to an impurity (such as oxidation reduction product) in the solid crystals. This wave was never obtained when a large excess of catechol was present.

To gather information as to the kinetic behavior of this wave the following precedure was used: $25 \mathrm{ml}$ of $1 \mathrm{M} \mathrm{NaClO}_{4}$ was deoxygenated, $0.010 \mathrm{~g}$ of solid $1: 3$ complex dissolved into it and current measurements 
were recorded at a previously fixed potential. In the cases where the

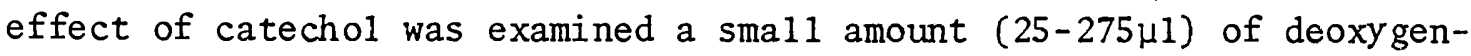
ated, pH-adjusted catechol was added to the cell after the solid complex had dissolved. In the case where excess As (V) was examined, the arsenate was present when the solid complex was dissolved. The $\mathrm{pH}$ of the set of measurements where excess As(V) was present was not the same as the $\mathrm{pH}$ in the other runs.

By assuming that the limiting current measurements are directly proportional to the concentration: of the $1: 3$ complex and that the rate of decay is first order in its concentration a plot of $-\ln \left(i-i_{r}\right)$ vs. $t / s e c$. was made. A summary of the results obtained is found in Table IV, where $k$ is a pseudo first order rate constant for the decay of the polarographic wave and $i_{0}$ is the current obtained by extrapolation to $t=0$.

It was found that the decay is first order in reducible species and, at least roughly, appears to be first order in hydrogen ion concentration. Added As(V) seems to have no effect on $k$ or $i_{0}$. The presence of excess catechol seems to have no effect on the rate of decay but does suppress the wave, that is decrease $i_{0}$. Phenol was found to have the same effect on the wave. Increasing the hydrogen ion concentration increases $i_{0}$, which may infer that it is a protonated species which undergoes charge transfer.

Measurements of $i$ vs. mercury height were made to try to determine if the limiting current is diffusion controlled. $0.500 \mathrm{~g}$ of solid complex was added to $50 \mathrm{ml} 1 \mathrm{M} \mathrm{NaClO}_{4} \mathrm{pH}=2.45\left(1 \mathrm{M} \mathrm{HClO}_{4}\right)$. Ten minutes after the preparation of this solution a polarographic scan was taken. Be- 


\section{TABLE IV}

SUMMARY OF THE KINETIC BEHAVIOR OF THE POLAROGRAPHIC WAVE OBTAINED FROM SOLUTIONS PREPARED FROM

\section{THE SOLID 1:3 COMPLEX}

Effect of Added Catechol

$\begin{array}{cccc}\begin{array}{r}\text { molarity of } \\ \text { added catechol }\end{array} & k\left(\times 10^{4}\right) /(\mathrm{s} \mu \mathrm{A})^{-1} & \mathrm{i}_{0} / \mu \mathrm{A} & \begin{array}{c}\text { correlation } \\ \text { coefficient }\end{array} \\ 0 & 5.8 & 5.5 & .9996 \\ 0 & 6.8 & 5.8 & .9987 \\ 0 & 7.0 & 5.9 & .9971 \\ 1 \times 10^{-3} & 6.1 & 4.5 & .9997 \\ 2 \times 10^{-3} & 5.6 & 4.0 & .9995 \\ 4 \times 10^{-3} & 6.2 & 3.2 & .9990 \\ 11 \times 10^{-3} & 6.8 & 1.8 & .9997\end{array}$

Effect of Added As (V)

$\begin{array}{cccc}\begin{array}{c}\text { molarity of } \\ \text { added As(V) }\end{array} & k\left(\times 10^{3}\right) /(\mathrm{s} \mu \mathrm{A})^{-1} & \mathrm{i}_{0} / \mu \mathrm{A} & \begin{array}{c}\text { correlation } \\ \text { coefficient }\end{array} \\ 0 & 1.1 & 7.8 & .9999 \\ 0.02 & 1.1 & 7.9 & .9996 \\ 0.05 & 1.1 & 7.8 & .9999\end{array}$

\section{Effect of pH}

$\begin{array}{lccr}\mathrm{pH} & \mathrm{k} /(\mathrm{s} \mu \mathrm{A})^{-1} & \mathrm{i}_{0} / \mu \mathrm{A} & \mathrm{T} /{ }^{\circ} \mathrm{C} \\ 2.2 & 7.0 \times 10^{-5} & 0.92 & 20 \\ 1.1 & 4.9 \times 10^{-4} & 5.2 & 19 \\ 0.2 & 4.0 \times 10^{-3} & 11.5 & 18\end{array}$




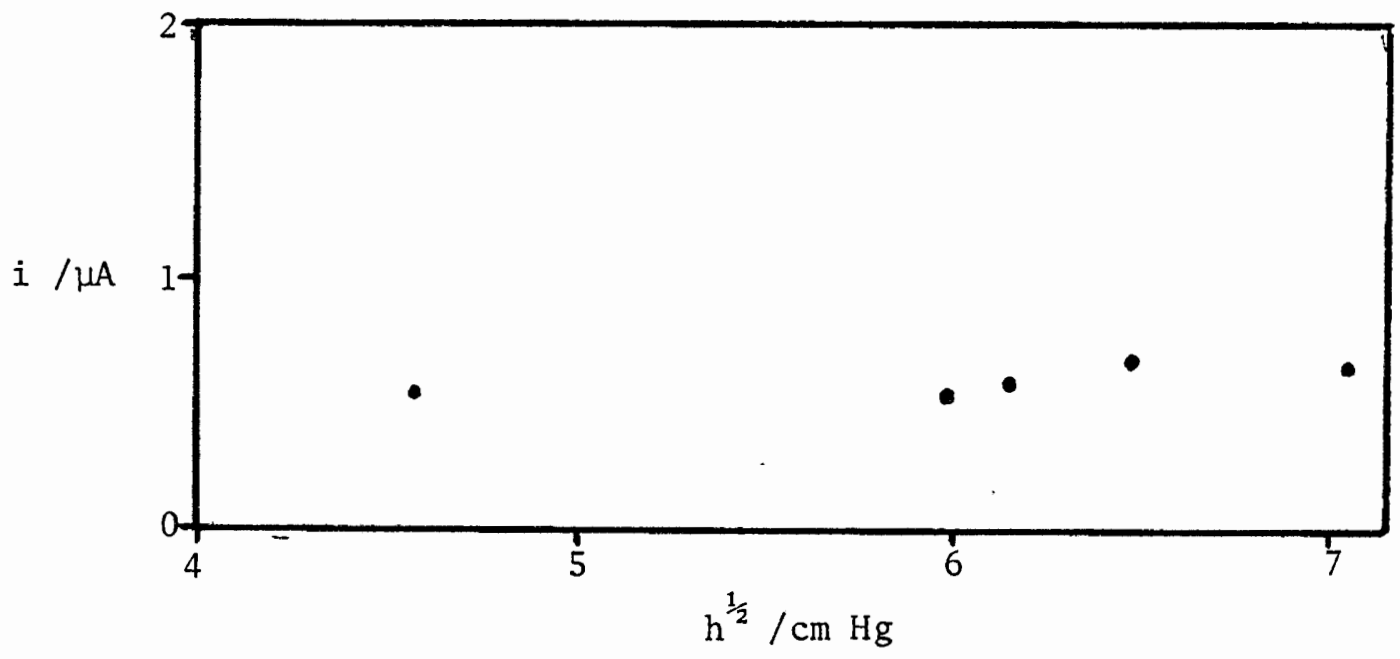

Figure 16. Effect of mercury height on the polarogram of a solution prepared from the $1: 3$ complex.

cause of the error involved in such measurements where the current is time dependent precise results were not possible but the results of plotting $i$ vs. $h^{\frac{1}{2}}$ in Figure 16 indicate that the wave is not simply diffusion controlled. 


\section{DISCUSSION}

In order to understand which complex gives rise to the polarographic wave, formation constants were necessary to determine the distribution of any species present. Calculation of these formation constants required an assumption of what complexes are present followed by an iteration procedure.

Potentiometric titrations were interpreted in terms of the types of complexes that might be present. Figure 2 shows that the first endpoint never shifts when solutions of arsenic acid containing catechol are titrated, though there is a gradual shift in the second endpoint. Only those complexes which either liberate a proton upon formation or have a $\mathrm{pK}_{\mathrm{a}}$ comparable to $\mathrm{pK}_{1}$ for arsenic acid need be considered noting that there is no shift in the first inflection point. Since the $\mathrm{pH}$ of the solution was lowered as increasing amounts of catechol were added the complexes must be more acidic than $\mathrm{H}_{3} \mathrm{AsO}_{4}$. These titration curves were not used for measurement of complexed As(V) for two main reasons. First, since complex formation is $\mathrm{pH}$ dependent (except where there is essentially $100 \% \mathrm{H}_{2} \mathrm{AsO}_{4}^{-}$), and second because of the overlap between the titration curve of catechol with that of $\mathrm{H}_{2} \mathrm{AsO}_{4}^{-}$.

The titrations of solutions prepared from solid $1: 3$ complex (Figure 3) show that the $1: 3$ complex is a moderately strong acid $(\mathrm{pK}<1)$, monoprotic, undergoes a slow dissociation, and because it dissociates completely in dilute solution, it is a weak complex. All these observations agree with the types of species assumed in the introduction. 
The one method that can be used to determine the amount of As(V) complexed when a given concentration of catechol is added to a solution of arsenic acid is to measure the concentration of protons liberated. Rather than use the change in $\mathrm{pH}$ to determine the amount of protons liberated any change in solution $\mathrm{pH}$ was followed by an addition of $\mathrm{NaOH}$ to return the solution to its original $\mathrm{pH}$. This introduces dilution errors $(<1 \%)$ but keeps data in terms of concentrations instead of activities. Using this method, at room temperature and ionic strength of $1 \mathrm{M}$, formation constants were calculated to be: $\beta_{1} \simeq 0.01, \beta_{2} \simeq 0.02$ and $\beta_{3}=7.5 \pm 1$, where $\beta_{1}$ and $\beta_{2}$ should be regarded as estimates since they are so small and depended upon data in the region subject to much experimental error. It will be shown later that the distribution curves resulting from these values are very much in agreement with the polarographic data. Also from these measurements it was found that no complex is appreciably protonated as low as $\mathrm{pH}=1$, so that $\mathrm{pK}_{\mathrm{a}}<1$.

There were many experimental problems associated with the measurements described in the preceding paragraph. It was not possible to know by independent means the uncomplexed catechol concentration. This meant that an iteration procedure had to be used, based upon estimates of the formation constants. The greater the As(V) concentration the more critical this correction, particularily when one considers that this term must be squared and cubed. The lower $\mathrm{pH}$ region $(1-2)$ is the most advantageous place to make the measurements, since in that region $\mathrm{H}_{3} \mathrm{AsO}_{4}$ is less dissociated, and knowledge of the absolute $\mathrm{pH}$ is not nearly as critical (being off $0.1 \mathrm{pH}$ unit at $\mathrm{pH}=3$ would result in a $26 \%$ difference in the amount of $\mathrm{H}_{3} \mathrm{AsO}_{4}$ believed present, at $\mathrm{pH}=1.5$ on Iy a 
$5 \%$ error would result). Unfortunately as the $\mathrm{pH}$ is decreased, higher As $(\mathrm{V})$ concentrations are needed to produce enough of a $\mathrm{pH}$ change to get adequate resolution on the $\mathrm{pH}$ meter. The experiments were done using the best compromise between these points.

A summary of formation constants reported by other researchers and those calculated in this work is given in Table V. Rais et al. (31), as was stated in the introduction, were inconsistant in their notation. The value given in paranthesis is this author's interpretation of their experimental results. Noting the agreement of this value with the value of $B_{3}$ estimated from solvent extraction (32) it appears that there was merely a notation error. The formation constant values from Votava and Bartusek (33) differ by some two orders of magnitude. The reason for this disagreement is their omission of a correction for uncomplexed catechol. When dealing with solutions as concentrated as 0.04M As(V) this correction becomes very important. Rias et al. (31) also made no correction for uncomplexed catechol in their calculation but used a much more dilute solution of arsenic acid (0.005M). Rias noted that as the concentration of $\mathrm{As}(\mathrm{V})$ was increased, the formation constant seemed to decrease, which was only due to the failure to correct for the uncomplexed catechol concentration. From the experimental data of Votava and Bartusek (33), formation constants were estimated, and are in much better agreement with the other tabulated values in Table V.

In light of the results up to this point it is of interest to go back and take a look at the experiments done by Jones et a1. (20-24). It is fairly clear that the $\mathrm{pK}_{\mathrm{a}}$ value they reported was obtained from 
TABLE V

COMPARISON OF EQUILIBRIUM CONSTANTS

$\begin{array}{llllllll}\text { Reference } & \beta_{1} & \mathrm{pK}_{\mathrm{a} 1} & \beta_{2} & \mathrm{pK}_{\mathrm{a} 2} & \beta_{3} & \mathrm{pK}_{\mathrm{a} 3} & \text { Method }\end{array}$

$1.4\left(10^{4}\right) \quad 1-1.4 \quad$ Potentiometric titration

$0.05<1$

$10 \pm 5$

$1-1.4$

Solvent extraction

$0.07<1 \quad$ Potentiometric titration

This work $\simeq 0.01<1 \simeq 0.02<1 \quad 7.5 \pm 1<1 \quad$ Potentiometric

Values in parenthesis were estimated from the experimental data reported.

titration of a solution in which the $1: 3$ complex had dissociated. The hydrolysis mechanism proposed was based on the increase in the solution $\mathrm{pH}$ as the complex dissociated. If they had observed that the complex is more acidic than arsenic acid they would have probably proposed that a complete dissociation was taking place. The rate of this dissociation, $k=0.006 \mathrm{~s}^{-1} \mathrm{M}^{-1}$, is essentially the same as the rate of the disappearance of the polarographic wave obtained from solutions prepared from $1: 3$ complex, $k=0.004 s^{-1} M^{-1}$. The presence of this wave is confusing as it is not found with any solutions prepared from combining seperate solutions of $A s(V)$ and catechol. The way its disappearance parallels the dissociation of the $1: 3$ complex seems to imply that the $1: 3$ complex can undergo charge transfer. One possibility is that the $1: 3$ complex can be adsorbed on the mercury and reduced. In the presence of excess catechol though, the catechol is preferentially adsorbed, perhaps because it is a neutral species and the bulky 1:3 complex for steric reasons cannot 
approach in the correct orientation to undergo reduction. This would explain why catechol and phenol have a suppressive effect on the limiting current (Table V).

The NMR temperature study of the 1:3 complex appears to have shown that there is either a distinct equilibrium between structure I and II in Figure 1, or at least some type of partial bonding in a coordinate position between a water molecule (or hydronium ion) and catechol. Lowering the temperature on 1 y $15^{\circ} \mathrm{C}$ gave a distinct shift, so that a singlet for the aromatic protons was formed. This infers that a tris chelate structure is indeed the most stable. Mason and Mason (26) observed that there was a singlet for the aromatic protons in the MMR spectra when the 1:3 complex was dissolved in dimethysulphoxide but a doublet when dissolved in $\mathrm{D}_{2} \mathrm{O}$ and could not explain the results. It is apparent that in a non-aqueous media there would be no reason to expect that structure I would be present. Mason points out that an equilibrium between structure $I$ and II is inconsistent with the slow rate of optical activity loss observed by Jones (20). This does not seem to be a valid argument as all experimental evidence indicates that there is an equilibrium between these structures and there is no evidence to the contrary.

The objective of this study was to identify the species that is polarographically reducible and explain the time-concentration dependency of the limiting current. As mentioned in the introduction, Roe (16) did a number of measurements with regard to the time, pH and catechol concentration dependency of the polarographic wave. It was found that varying only the catechol concentration at $\mathrm{pH}=1$ the limiting 


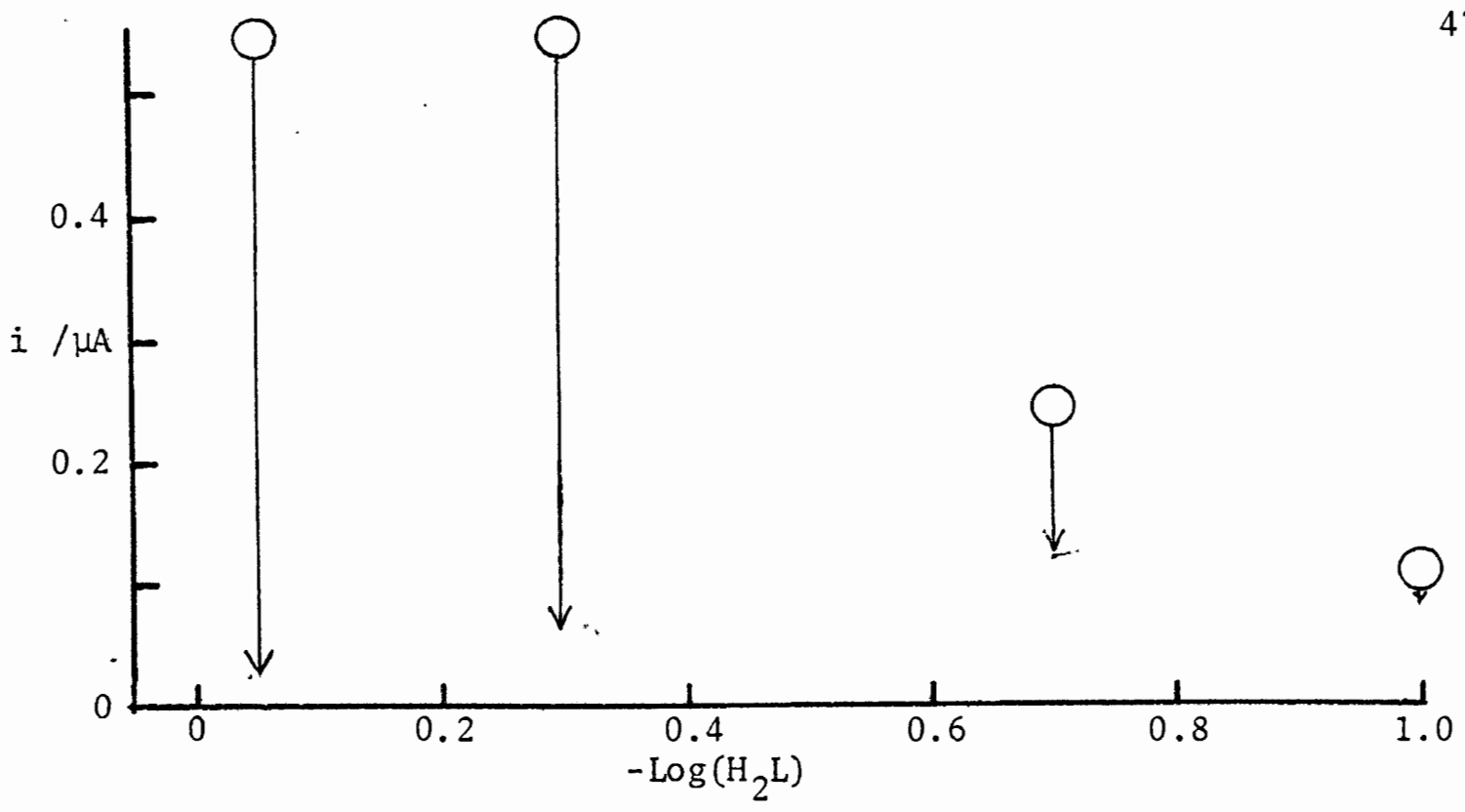

Figure 17. Current dependence on time and catechol concentratration. 0.2mM As(V), $0.1 \mathrm{M} \mathrm{HClO}_{4}, 0.9 \mathrm{M} \mathrm{NaCiO}_{4}$ (16)

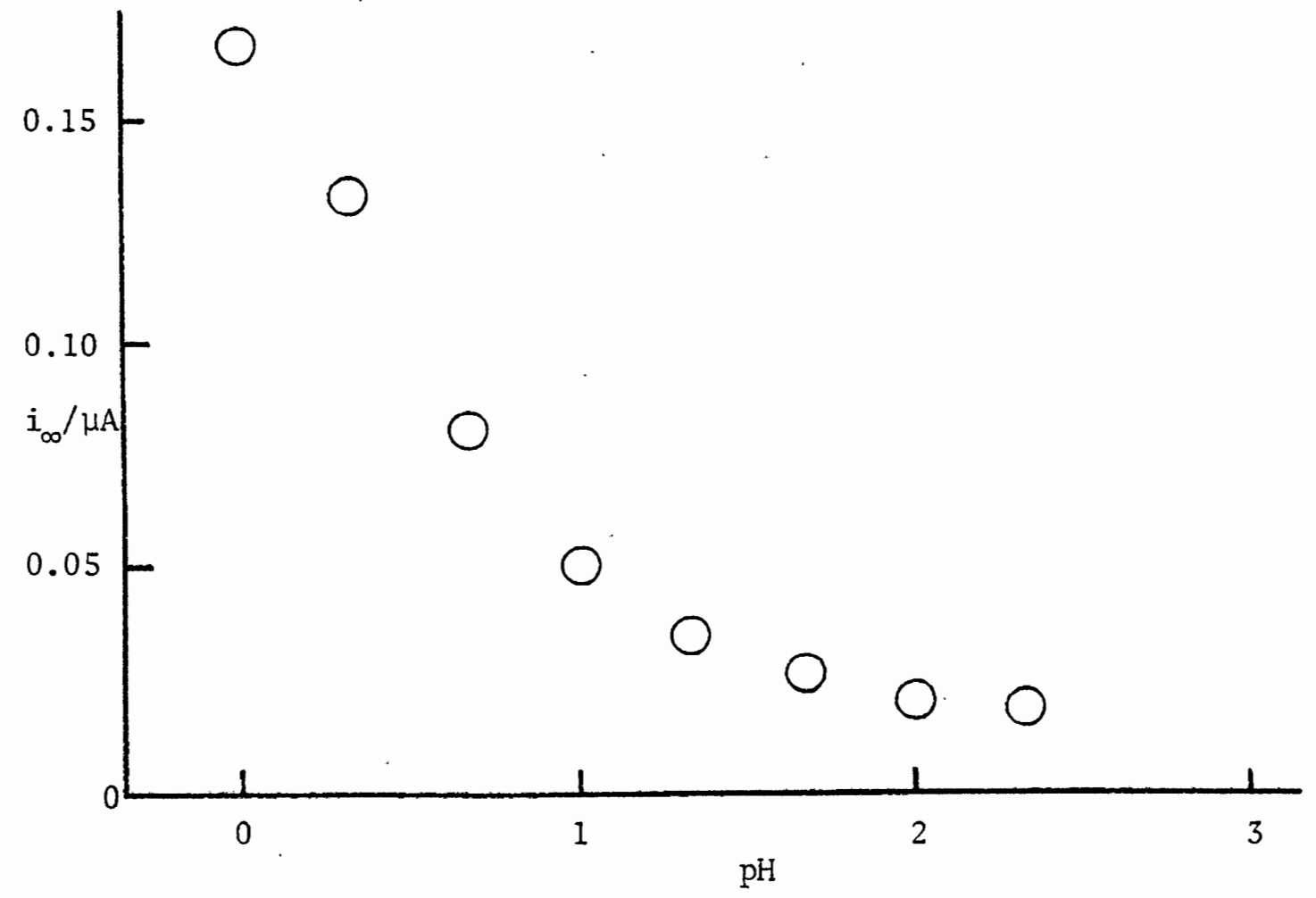

Figure 18. Dependence of limiting current on $\mathrm{pH} .0 .20 \mathrm{mM}$ As(V), $0.5 \mathrm{M}$ catechol, $\mathrm{I}=1 \mathrm{M}\left(\mathrm{NaClO}_{4}\right)$. (16) 
current was initially at some peak value, $i_{0}$, and decayed at different rates to some final value $i_{\infty}$. The value of $i_{0}$ did not change going from 0.5-1.0M catechol. This data is summarized if Figure 17. It was also found that in $0.5 \mathrm{M}$ catechol, $i_{\infty}$ increased as the $\mathrm{pH}$ was varied from $2.3-$ 0 , although this effect seems to level off if the $\mathrm{pH}$ is above 2 . The $i_{0}$ associated with all the samples where $0.5 \mathrm{M}$ catechol was used was the same at all the $\mathrm{pH}^{\prime} \mathrm{s}$ investigated. The polarographic measurements made in this experiment were of $i_{\infty}$. Figure 18 shows this variation of $i_{\infty}$ as a function of $\mathrm{pH}$. Going from $\mathrm{pH}=2$ to $\mathrm{pH}=0$ there is a ten fold increase in $i_{\infty}$. Figure 13 shows the variation in $i_{\infty}$ as a function of both $\mathrm{pH}$ and catechol concentration. The current at $\mathrm{pH}=1$ is about three times that at $\mathrm{pH}=2$. At $\mathrm{pH}=1$ the peak value of $i_{\infty}$ is at a catechol concentration of $0.25 \mathrm{M}$ while at $\mathrm{pH}=2$ the peak is at a catechol concentration of about $0.15 \mathrm{M}$. It was also found that at $\mathrm{pH}=1$ the limiting current is kinetically controlled whereas as $\mathrm{pH}=2$ it is more diffusion controlled. In order to tie the formation constant information together with the polarographic data it is first necessary to go to Table I and II. From these distribution figures it can be seen that at $\mathrm{pH}=1$ the maximum amount of $1: 1$ complex occurs at about $0.2 \mathrm{M}$ catechol and at $\mathrm{pH}=2$ this maximum occurs at a catechol concentration of $0.1 \mathrm{M}$. These maxima are in very close agreement with the data from the preceding paragraph.

In all cases $i_{0}$ relates to the total amount of As(V) complexed, the current decaying as the higher ordered complexes are formed. Assuming that when all the $A s(V)$ is complexed $i_{0}=i_{\max }$ it is possible to tell how much $A s(V)$ is complexed from the fraction $i_{0} / i_{\max }$. Table I predicts that about $40 \%$ of the As(V) will be complexed at a catechol 
concentration of $0.2 \mathrm{M}, \mathrm{pH}=1$. From Figure 17 at the same catechol concentration $i_{0} / i_{\max }=0.45$.

According to the formation constants the amount of $1: 1$ complex should decrease as the $\mathrm{pH}$ decreases (in the $\mathrm{pH}$ range where $\mathrm{pH}<4$ ). This is not the case with the $i_{\infty}$ as is seen in Figure 18. In attempting to explain the rise in the limiting current as the $\mathrm{pH}$ decreases one is forced to consider three possibilities. First a simple protonation reaction may be taking place. As the pH decreases the equilibria would shift in favor of the protonated form. If this were the case $i_{\max }$ would also increase, which is not the case. Another situation is the formation of the 1:1 complex from $A s(V)$ as the 1:1 complex concentration is depleted at the mercury surface. Roe (16) found that the initial rise to $i_{0}$ is slower at higher $\mathrm{pH}^{\prime} \mathrm{s}$ which would mean that as the $\mathrm{pH}$ decreased complex formation is faster. This, though, is inconsistant with the observation that the kinetic current is less at higher catechol concentrations. The last possibility is the formation of $1: 1$ complex from the dissociation of the $1: 2$ and $1: 3$ complex. Jones et al. (24) found that the rate of hydrolysis is first order dependent upon hydrogen ion concentration. The effect of catechol is also agreeable with this process.

Assuming the protonated 1:1 species is the one which undergoes charge transfer the following equilibria to describe the formation of this species from the 1:3 species can be written:

$$
\begin{aligned}
& 4 \mathrm{H}_{2} \mathrm{O}+\mathrm{AsL}_{3}^{-} \underset{\mathrm{k}_{\mathrm{b}}}{\stackrel{\mathrm{k}_{f}}{=}} \text { As }(\mathrm{OH})_{4} \mathrm{~L}^{-}+2 \mathrm{H}_{2} \mathrm{~L}_{\mathrm{f}}=6.0\left(10^{-3}\right) \quad \frac{\mathrm{k}_{\mathrm{f}}}{\mathrm{k}_{\mathrm{b}}}=\frac{\beta_{1}}{\beta_{3}}=.0013 \\
& \text { As }(\mathrm{OH})_{4} \mathrm{~L}^{-}+\mathrm{H}^{+} \text {fast }_{\mathrm{HAs}(\mathrm{OH})_{4} \mathrm{~L}}^{\text {reducible }}
\end{aligned}
$$


The rate of the forward reaction is being assumed to be equal to the rate of hydrolysis Jones et al. observed (24).

Meites (34) gives an equation which enables the calculation of a kinetic current, $i_{k}$, given the pseudo-first order rate constants $k_{f}^{\prime}$ and $\mathrm{k}_{\mathrm{b}}^{\prime}$.

$$
\begin{gathered}
i_{k}=493 n D^{\frac{1}{2}} m^{\frac{2}{3}} t^{\frac{2}{3}} \mathrm{C}\left(k_{f}^{\prime} / k_{b}^{\frac{1}{2}}\right) \\
k_{f}^{-}=k_{f}\left(H^{+}\right) \\
k_{b}^{-}=k_{b}\left(H_{2} L\right)^{2}
\end{gathered}
$$

All symbols have their usual meaning and $C$ is the concentration of the 1:3 species. Since by changing the catechol concentrations the amount of $1: 3$ complex present would change, only pH effects will be investigated. Table VI shows how the relative kinetic current changes with respect to $\mathrm{pH}$.

\section{TABLE VI}

KINETIC CURRENT DEPENDENCE ON pH

$\begin{array}{cc}\mathrm{pH} & \left(\mathrm{k}_{\mathrm{f}}^{-} / \mathrm{k}_{\mathrm{b}}^{-\frac{1}{2}}\right)\left(10^{4}\right) \\ 3 & 1.8 \\ 2 & 5.6 \\ 1 & 18 \\ 0 & 56\end{array}$

The results of Table VI predict a three fold rise in $i_{k}$ going from $\mathrm{pH}=2-1$. Comparing this with the data in figure 13 shows good agreement. Figure 18 shows about a three fold rise in $i_{\infty}$ going from $\mathrm{pH}=2-1$ and a ten fold rise going from $\mathrm{pH}=2-0$. This is exactly the 
pattern predicted from the results in Table VI.

The correlation between the polarographic observation and formation constant and rate data is very convincing. The $1: 1$ complex is the reducible species in the presence of excess catechol. The 1:3 species, predominant under these conditions, is not able to undergo charge transfer by a diffusion controlled mechanism, if at a1l.

The system seems suitable for analytical application for the simultaneous determination of $A s(V)$ and $A s(I I I)$. One possible procedure is as follows. The sample is deoxygenated and acidified to $\mathrm{pH}=1$; deoxygenated, concentrated catechol is added to a concentration of about 0.5M; this insures maximum $i_{0}$. Current readings are then taken for a couple of minutes at $E_{\mathrm{de}} v s$. $S C E=-0.4 \mathrm{v}$. By finding the residual current at this potential later, a plot of $-\ln \left(i-i_{r}\right)$ vs. $t$ is made, where $i$ is the current at a given time $t$, and $i_{r}$ is the residual current. By extrapolation to $t=0$, $i_{0}$ will give a means of obtaining consistent results. This will yield the As(V) concentration. The solution is allowed to set for about 15 minutes, at which time a scan is made to give the residual for the $A s(V)$ current readings and to determine the amount of As(III) present. This method should easily be able to detect $0.5 \mu \mathrm{M}$ concentrations of As(V) and As(III). 


\section{REFERENCES}

1. Grindley, J., Annl. Appl. Biol., 33, 103 (1946) .

2. Hayes, W.J., Essays in Toxicology, Academic Press, New York (1972).

3. Kirk Othmer Encyclopedia of Chemical Technology, 2nd ed., Intersciencè Publishers, New York (197,3).

4. Belcher, R., Bogdanski, S.L., Henden, E., Townshind, A., Anal. Chem. Acta, 92(1), 33 (1977).

5. Welz, B., Chim. Ind. 59(11), 771 (1977).

6. Zeman, A., Stary, J. and Kratzer, K., Radiochem. Radioanal. Lett., $\underline{4}(1), 1$ (1970).

7. Stara, V. and Stary, J., Talanta, 17, 341 (1970).

8. Talmi, Y. and Feldman, C., "The Determination of Traces of Arsenic: A Review," in "Arsenical Pesticides," Woolson, E.A., Ed., American Chemical Society, Washington D.C., (1975).

9. Kang, S., Masters Thesis, Portland State University (1974).

10. Bess, R., Ingolic, K., Flannery, J. and Ridgeway, T.H., Anal. Lett., $10(5), 415$ (1977).

11. Bess, R., Ingolic, K., Flannery, J. and Ridgeway, T.H., Anal. Lett., 9 (12), 1091 (1966).

12. Davis, P.H., Dulude, G.R., Griffin, R.M., Matson, W., Zink, E.W., Anal. Chem., 50(1), 137 (1978).

13. Meites, L., J.Amer. Chem. Soc., 76 (23), 5927 (1954) .

14. White, M. and Bard, A., Ana1. Chem., 38(1), 61 (1966).

15. Meyers, D.J. and Osteryoung, J., Anal. Chem., 45, 267 (1973)

16. Roe, D.K., Personal communication.

17. Weinland, R.F. and Heinzler, J., Ber., 52, 1316 (1919).

18. Rosenheim, A. and Plato, W., Ber., 58, 2000 (1925). 
19. Reihlen, H., Sapper, A. and Kal1, G.A., Z. anorg. allgem Chem., $144,218,(1925)$.

20. Craddock, J. and Jones, M., J. Am. Chem. Soc., 83, 2839 (1961).

21. Craddock, J. and Jones, M., J. Am. Chem. Soc., 84, 1098 (1962).

22. Larkins, T.H., Martin, C.E. and Jones, M., Inorg. Chem., $2(3)$, 554 (1963).

23. Larkins, T.H. and Jones, M., Inorg. Chem., 2, 142 (1963).

24. Jones, M., Johnson, W.L. and Larkins, T.H., Inorg. Chem., 4(7), 1051 (1965).

25. Mann, F.G. and Watson, J., J. Chem. Soc., 505 (1947).

26. Mason, J. and Mason S.F., Tetradon., 23(4), 1919 (1967).

27. Ito, T., Inorg. Nuc1. Chem. Lett., 7, 1097 (1971).

28. Wieber, Von M. and Ma11on T., Z. anorg. allg. Chem., 424, 27 (1976).

29. Mann, F.G., The Heterocyclic Derivitives of Phosphorous, Arsenic, Antimony and Bismuth, 2nd., S.551, Wiley-Interscience, New York-London-Sydney-Toronto (1970).

30. Rais, J., Selucky, P. and Drazanova, S., Radiochem. Radioanal. Lett., 4(4), 195 (1970).

31. Rais, J., Selucky, P. and Drazanova, S., J. Inorg. Nuc1. Chem., 33, 3087 (1971).

32. Krtil, J. and Rais, J., J. Radioanal. Chem., 27, 47 (1975).

33. Votava, J. and Bartusek, M., Collect. Czech. Chem. Comm., 42, $620(1976)$.

34. Meites, L., Polarographic Techniques, John Wiley \& Sons, New York, 1965.

35. Crow, D.R., Polarography of Metal Complexes, Academic Press, London, New York (1969). 


\section{APPENDIX}

Definition of Equilibria:

$$
\mathrm{H}_{3} \mathrm{AsO}_{4}+\mathrm{nH}_{2} \mathrm{~L} \underset{\mathrm{B}_{n}}{=} \mathrm{H}^{+}+\mathrm{AsL}_{n}(\mathrm{OH})_{6-2 \mathrm{n}}^{-}+(\mathrm{n}-1) \mathrm{H}_{2} \mathrm{O} ; \mathrm{n}=1,2,3 \text {. }
$$

OR:

$$
\begin{gathered}
\mathrm{H}_{3} \mathrm{AsO}_{4}+\mathrm{nH}_{2} \mathrm{~L} \Rightarrow \mathrm{H}^{+}+\mathrm{AsO}_{3-\mathrm{n}_{\mathrm{n}}^{-}}+(\mathrm{n}+1) \mathrm{H}_{2} \mathrm{O} \\
\mathrm{HAsL}_{\mathrm{n}}(\mathrm{OH})_{6-2 \mathrm{n}} \overline{\overline{\mathrm{K}}}_{\mathrm{an}}^{+}+\mathrm{AsL}_{\mathrm{n}}\left(\mathrm{OH}_{6}^{-}-2 \mathrm{n}\right. \\
\mathrm{H}_{3} \mathrm{AsO}_{4} \overline{\overline{\mathrm{K}}}_{1} \mathrm{H}^{+}+\mathrm{H}_{2} \mathrm{AsO}_{4}^{-}
\end{gathered}
$$

Derivation of Catechol Arsenate Relationship:

Mass balance for As (V)

(1) $\mathrm{C}_{\mathrm{As}}=\left(\mathrm{H}_{3} \mathrm{AsO}_{4}\right)+\left(\mathrm{H}_{2} \mathrm{AsO}_{4}^{-}\right)+\left(\mathrm{AsL}(\mathrm{OH})_{4}^{-}\right)+\left(\mathrm{HAsL}(\mathrm{OH})_{4}\right)+\left(\mathrm{AsL}_{2}(\mathrm{OH})_{2}^{-}\right)+$ $\left(\mathrm{HAsL}_{2}(\mathrm{OH})_{2}\right)+\left(\mathrm{AsL}_{3}^{-}\right)+\left(\mathrm{HAsL}_{3}\right)$

By substituting the appropriate equilibria expressions and rearranging

(2) $Y=C_{A s}\left(\mathrm{H}^{+}\right) /\left(\mathrm{H}_{3} \mathrm{AsO}_{4}\right)=\left(\mathrm{H}_{2} \mathrm{~L}\right)\left\{\mathrm{B}_{1}+\mathrm{B}_{1}\left(\mathrm{H}^{+}\right) / \mathrm{K}_{\mathrm{al}}\right\}+\left(\mathrm{H}_{2} \mathrm{~L}\right)^{2}$.

$$
\left\{\beta_{2}+\beta_{2}\left(H^{+}\right) / K_{a 2}\right\}+\left(H_{2} L\right)^{3}\left\{\beta_{3}+\beta_{3}\left(H^{+}\right) / K_{a 3}\right\}+(H+)+K_{1}
$$

If $\mathrm{K}_{\text {an }} \gg\left(\mathrm{H}^{+}\right)$

(3) $Y=\left(\mathrm{H}_{2} \mathrm{~L}\right) \mathrm{B}_{1}+\left(\mathrm{H}_{2} \mathrm{~L}\right)^{2} \mathrm{~B}_{2}+\left(\mathrm{H}_{2} \mathrm{~L}\right)^{3} \mathrm{~B}_{3}+\mathrm{K}_{1}+\left(\mathrm{H}^{+}\right)$

Calculation of Base Correction:

$$
\mathrm{B}_{\text {corr }}=\left(\mathrm{V}_{f}-30.0\right)\left(\mathrm{H}^{+}\right) / \mathrm{V}_{f}+\mathrm{B}_{\text {uncorr }} ; \mathrm{B}_{\text {uncorr }} \text {, amount of base }
$$

used to adjust the $\mathrm{pH}, \mathrm{v}_{f}$, final volume. 
Calculation of $\left(\mathrm{H}_{3} \mathrm{AsO}_{4}\right)$ :

(5)

$\left(\mathrm{H}_{3} \mathrm{AsO}_{4}\right)_{\mathrm{I}}=\alpha_{0} \mathrm{C}_{\mathrm{As}}-\mathrm{B}_{\text {corr }} \quad \alpha_{0}=$ fraction of $\mathrm{As}(\mathrm{V})$ as $\mathrm{H}_{3} \mathrm{AsO}_{4}$

If $\mathrm{K}_{\text {an }}>/>\left(\mathrm{H}^{+}\right)$an iterative procedure must be used after an initial estimation of the $K_{a}$ values

$$
\begin{aligned}
\left(\mathrm{H}_{3} \mathrm{AsO}_{4}\right)= & \alpha_{0} \mathrm{C}_{\mathrm{As}}-\mathrm{B}_{\text {corr }}-\left(\mathrm{H}_{3} \mathrm{AsO}_{4}\right)_{\mathrm{I}}\left\{\mathrm{B}_{1}\left(\mathrm{H}_{2} \mathrm{~L}\right) / \mathrm{K}_{\mathrm{a} 1}+\beta_{2}\left(\mathrm{H}_{2} \mathrm{~L}\right)^{2} / \mathrm{K}_{\mathrm{a} 2}\right. \\
& \left.+\beta_{3}\left(\mathrm{H}_{2} \mathrm{~L}\right){ }^{3} / \mathrm{K}_{\mathrm{a} 3}\right\}
\end{aligned}
$$

This equation would iterate until there was less than a $0.5 \%$ change in $\left(\mathrm{H}_{3} \mathrm{AsO}_{4}\right)$.

Calculation of Uncomplexed Catechol Concentration, $\left(\mathrm{H}_{2} \mathrm{~L}\right)$ :

Mass balance equation for catechol;

(7) $\mathrm{C}_{\mathrm{H}_{2} \mathrm{~L}}=\left(\mathrm{H}_{2} \mathrm{~L}\right)+\left(\mathrm{HAsL}(\mathrm{OH})_{4}\right)+\left(\mathrm{AsL}(\mathrm{OH})_{4}^{-}\right)+2\left(\mathrm{HAsL}_{2}(\mathrm{OH})_{2}\right)+$

$$
2\left(\mathrm{AsL}_{2}(\mathrm{OH}) \overline{2}\right)+3\left(\mathrm{HAsL}_{3}\right)+3\left(\mathrm{AsL}_{3}^{-}\right)
$$

Substituting the appropriate equilibria expressions and rearranging;

$$
\begin{aligned}
\left(\mathrm{H}_{2} \mathrm{~L}\right)= & \mathrm{C}_{\mathrm{H}_{2} \mathrm{~L}}-\left(\mathrm{H}_{3} \mathrm{AsO}_{4}\right)\left\{\mathrm{B}_{1}\left(\mathrm{H}_{2} \mathrm{~L}\right) / \mathrm{K}_{\mathrm{a} 1}+\beta_{1}\left(\mathrm{H}_{2} \mathrm{~L}\right) /\left(\mathrm{H}^{+}\right)+\right. \\
& 2 \mathrm{~B}_{2}\left(\mathrm{H}_{2} \mathrm{~L}\right)^{2} / \mathrm{K}_{\mathrm{a} 2}+2 \mathrm{~B}_{2}\left(\mathrm{H}_{2} \mathrm{~L}\right)^{2} / \mathrm{K}_{\mathrm{a} 2}+3 \beta_{3}\left(\mathrm{H}_{2} \mathrm{~L}\right)^{3} / \mathrm{K}_{\mathrm{a} 3}+ \\
& \left.3 \beta_{3}\left(\mathrm{H}_{2} \mathrm{~L}\right)^{3} /\left(\mathrm{H}^{+}\right)\right\}
\end{aligned}
$$

Once again an iterative procedure is used, the initial guess for

$\left(\mathrm{H}_{2} \mathrm{~L}\right)$ is based upon the assumption that there is predominately a $1: 3$ complex present.

$$
\left(\mathrm{H}_{2} \mathrm{~L}\right)_{\mathrm{I}}=\mathrm{C}_{\mathrm{H}_{2} \mathrm{~L}}-3 \mathrm{~B}_{\text {corr }} / \alpha_{0}
$$

The iteration proceeds until there is less than a $1 \%$ change in the $\left(\mathrm{H}_{2} \mathrm{~L}\right)$ concentration.

Realizing that it was possible for the complexes to have $K_{a}$ values in the range where they may be protonated to some extent, equation (6) was used in the calculations. Since $\left(\mathrm{H}_{2} \mathrm{~L}\right)$ is used in this equation, an estimation, using equation (9), was initially made. 
The entire procedure was programmed onto a Tektronix 31 programable calculator and essentially consisted of a triple iteration; iteration for $\left(\mathrm{H}_{3} \mathrm{AsO}_{4}\right)$ and $\left(\mathrm{H}_{2} \mathrm{~L}\right)$, then since the calculation of $\left(\mathrm{H}_{3} \mathrm{AsO}_{4}\right)$ depends on $\left(\mathrm{H}_{2} \mathrm{~L}\right)$ the entire procedure repeated until there was less than $0.5 \%$ change in either value. This program would also compare an experimentally determined $\left(\mathrm{H}_{3} \mathrm{AsO}_{4}\right)$ value with one calcullated using equation. (2), which indicated what formation constants may need alteration. The calculations become simplified if $\mathrm{K}_{\mathrm{an}} \ll\left(\mathrm{H}^{+}\right)$, in which case only an iteration for $\left(\mathrm{H}_{2} \mathrm{~L}\right)$ is needed.

Distribution Curve Calculation:

Calculation of the distribution values of all forms of arsenate in the presence of catechol was done using equation (2) assuming $C_{A s}=1$, and the appropriate equilibrium expressions. 


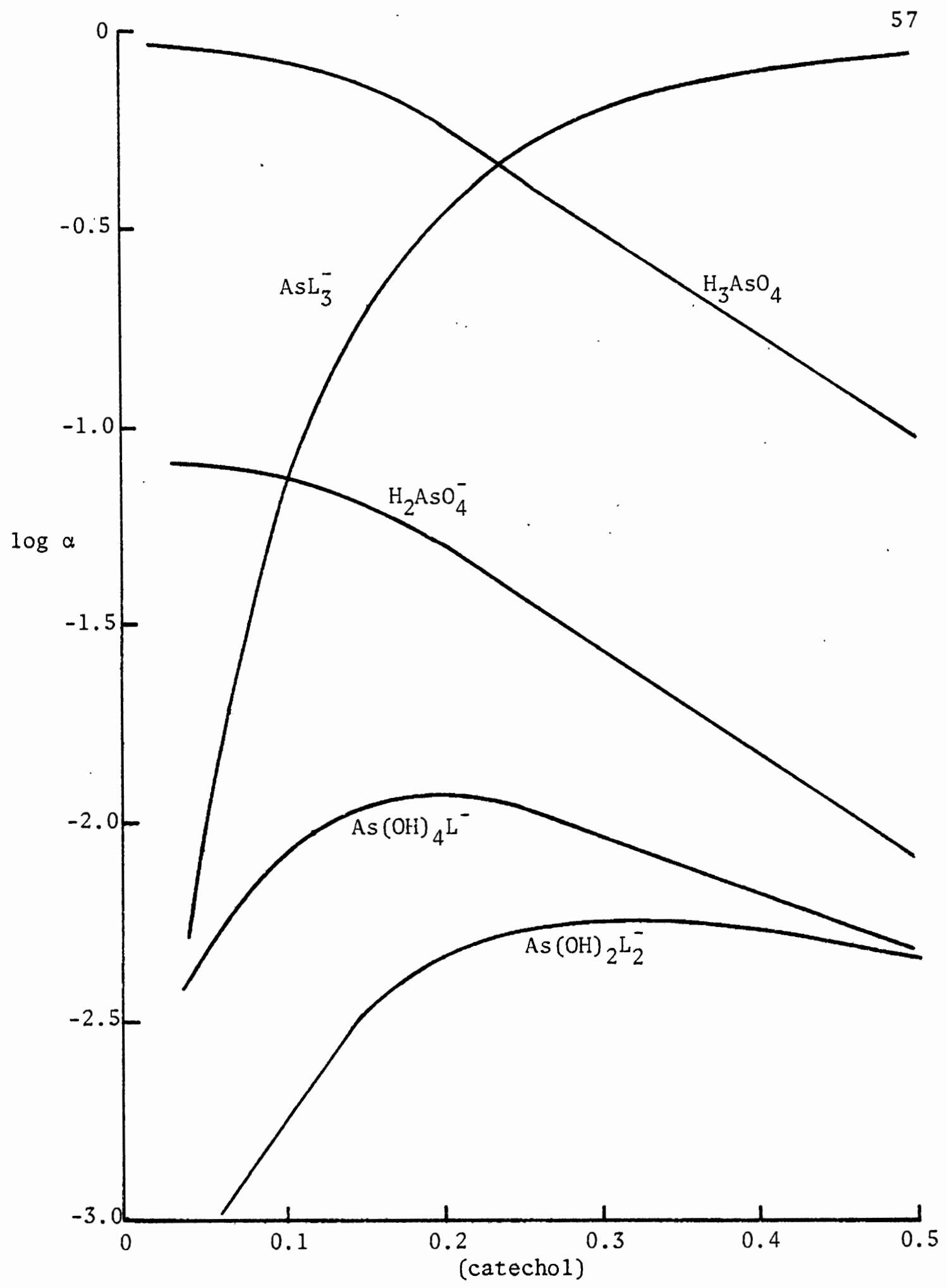

Figure 19. Distribution curves for As(V)-catechol system, $\mathrm{pH}=1$. 


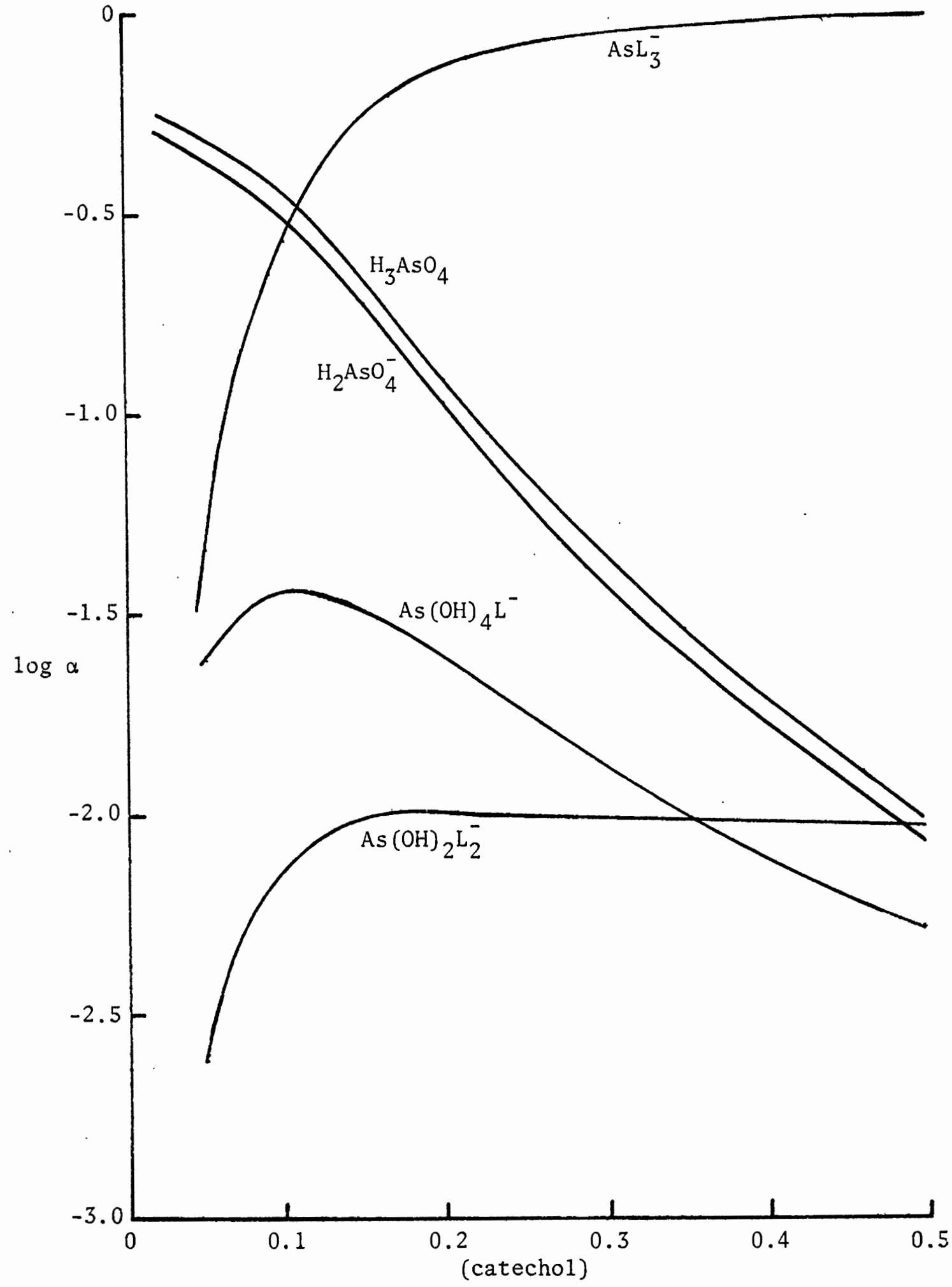

Figure 20. Distribution curves for $\mathrm{As}(\mathrm{V})$-catechol system, $\mathrm{pH}=2$. 